\title{
1 Pore-scale capillary pressure analysis using multi-scale X-ray 2 micromotography
}

4 Charlotte Garing ${ }^{1}$, Jacques A. de Chalendar ${ }^{1}$, Marco Voltolini ${ }^{2}$, Jonathan B. Ajo5 Franklin $^{2}$, Sally M. Benson ${ }^{1}$

$6{ }^{1}$ Stanford University, Energy Resources Engineering, Green Earth Sciences Bldg. Rm 50, 367 Panama 7 Street, Stanford, CA 94305

$8{ }^{2}$ Lawrence Berkeley National Laboratory, Earth and Environmental Sciences, 1 Cyclotron Road, 9 MS74R316C, Berkeley, CA 94720

10 cgaring@stanford.edu, jdechalendar@stanford.edu, mvoltolini@lbl.gov, JBAjo-Franklin@lbl.gov,

11 smbenson@stanford.edu

12

\section{Abstract}

A multi-scale synchrotron-based X-ray microtomographic dataset of residually trapped air after gravity-driven brine imbibition was acquired for three samples with differing pore topologies and morphologies;image volumes were reconstructed with voxel sizes from $4.44 \mu \mathrm{m}$ down to $0.64 \mu \mathrm{m}$. Capillary pressure distributionsamong the population of trapped ganglia were investigated by calculating interfacial curvature in order to assess the potential for remobilization of residually-trapped non-wetting ganglia due to differences in capillary pressure presented by neighbor ganglia. For each sample, sintered glass beads, Boise sandstone and Fontainebleau sandstone, sub-volumes with different voxel sizes were analyzed to quantify air/brine interfaces and interfacial curvatures and investigate the effect of image resolution on both fluid phase identification and curvature estimates. Results show that the method developed for interfacial curvature estimation leads to reliable capillary pressure estimates for gas ganglia. Higher resolution images increase confidence in curvature calculations, especially for the sandstone samples that display smaller gas-brine interfaces which are then represented by a higher number of voxels when imaged with a micron or sub-micron voxels size. The analysis of subvolumes from the Boise and Fontainebleau dataset highlights the presence of a residuallytrapped gas phase consisting of ganglia located in one or few pores and presenting significantly different capillary pressures, especially in the case of Fontainebleau sandstone. As a result, Ostwald ripening could occur, leading to gas transfer from ganglia with higher capillary pressure to surrounding ganglia with lower capillary pressures. More generally, at the pore-scale, most gas ganglia do present similar capillary pressures and Ostwald ripening would then not represent a major mechanism for residually-trapped gas transfer and remobilization.

\section{Keywords}

carbon storage, multiphase flow, residual trapping, interfacial curvature, capillary pressure, X-ray microtomography

\section{Introduction}

A critical aspect of geological carbon sequestration is the estimation of $\mathrm{CO}_{2}$ plume mobility and extent after injection has ceased. This estimation is particularly important in the context of open storage systems or systems in close proximity to possible migration 
1 pathways e.g. permeable faults. After an initial drainage phase during injection, models

2 typically posit that substantial $\mathrm{scCO}_{2}$ volumes are trapped as the plume moves under 3 buoyant forces during brine imbibition (Kumar et al., 2005; Juanes et al., 2006; Hesse et 4 al., 2008; Celia and Nordbotten, 2009). Conventional multi-phase flow models assume until they dissolve into the brine phase (Goodman et al., 2011), as under reservoir flow conditions, viscous forces are usually not sufficient for mobilization. However, multiple physiochemical mechanisms exist which could potentially invalidate this assumption including $\mathrm{scCO}_{2}$-induced transitions in wetting behavior (Kim et al., 2012; Wan et al., 2014; Wang et al., 2016), dissolution-induced ganglia size reduction (DePaolo and Cole, 2013), and inter-ganglia gas transfer via Ostwald ripening (Epstein and Plesset, 1950).In addition, recent findings from fast synchrotron-based X-ray computed microtomography (Armstrong et al., 2014; Rucker et al., 2015) and micromodel studies (Armstrong and berg, 2013) show that non-local cooperative displacement processes during water flooding have a large impact on pore scale fluid distributions and ganglion dynamics and could potentially affectthe stability of a trapped non-wetting phase.

In this study, we seek to develop experimental methods for improving the understanding of one of these mechanisms, the potential for Ostwald ripening of the residually trapped $\mathrm{CO}_{2}$ phase in porous media. Ostwald Ripening of gas bubbles in aqueous solutions has been extensively studied in homogeneous bulk media where dispersed particles of a second phase exist in a saturated solution, and where the bigger bubbles tend to grow at the expense of the smaller ones (Epstein and Plesset, 1950; Greenwood, 1956; Lifschitz and Slyozov, 1961; Voorhees, 1985; Schmeltzer and Schweitzer, 1987; Moller et al., 1998). In porous media, the presence of walls changes the process significantly, mainly because capillary pressure, the driver for ripening, is no longer only a function of the particle radius but also of pore topology and size.Few attempts have been made to extend the study of Ostwald ripening process to porous media. Most often, the process is either neglected (Andrew et al., 2014a), studied in a context where other mechanisms like a constant pressure decline in the liquid play a disproportionate role (Li and Yortsos, 1991; 1995; Dominguez et al., 2000), or studied in a context where cluster growth stops or is strongly inhibited once there is significant interaction with the porous matrix walls, for viscous polymers and crystals growing in a solid matrix for instance (Schmeltzer et al., 1995; Moller et al., 1998). Goldobin and Brilliantov (2011) investigated the diffusion of gas in porous media using mean thermodynamic properties, but did not account for porescale effects.

Ostwald ripening will be driven by differences in capillary pressure between gas ganglia, and subsequent diffusion of dissolved gasthrough the aqueous phase. Capillary pressure, which denotes the difference in pressure between a non-wetting and a wetting fluid (respectively $\mathrm{CO}_{2}$ and brine in the case of interest), is expressed by the Young-Laplace equation $P_{c}=P_{n w}-P_{w}=2 \sigma \kappa$, where $\sigma$ is the interfacial tension and $\kappa$ is the mean curvature of the interface between the two fluids.In a bulk liquid medium, a bubble of gas istypically spherical and its curvature is therefore directly linked to the bubble size. Porous media, however,exhibit a variety of complex geometries for which no simple analytical solution exists to describe the interface between two immiscible fluids. As 
1 capillary pressures inside individual non-wetting phase ganglia strongly depend on pore 2 geometry and topology (Bear, 1972), pore-scale investigations are requiredin order to 3 understand and measure the distribution of capillary pressure in disconnected trapped 4 ganglia of non-wetting phase, which is a critical question to assess Ostwald ripening 5 mechanism.

Due to significant improvements over the last decades and its non-destructive characteristic, X-ray microtomography has become the foremost imaging techniquefor the visualization and quantification of pore-scale structures and processes as well as providing input to pore-scale modeling (Blunt et al., 2013; Cnudde and Boone, 2013; Wildenschild and Sheppard, 2013, Schluter et al., 2014). Previous authors investigated residual trapping at the pore-scale using X-ray microtomography(Prodanovic et al., 2007; Kumar et al., 2010; Iglauer et al., 2011; Tanino and Blunt, 2012; Georgiadis et al., 2013; Chaudhary et al., 2013; Andrew et al., 2014a; Rücker et al., 2015; Herring et al. 2016, Schlüter et al., 2016).In particular, all ofthese studies show thatthe residually-trapped non-wetting phase takes the form of ganglia with various sizes and complicated irregular shapes, highlighting the complexity of the non-wetting and wetting phase interface geometry, as well as of the angle both fluids form with the solid surface.

Armstrong et al. (2012a) proposed a first method to calculate interfacial curvature using synchrotron-based X-ray microtomography images of water and oil in a glass beads packed column with a voxel size of $13 \mu \mathrm{m}$. They compared macro-scale capillary pressures measured via pressure transducer to micro-scale capillary pressures measured via interfacial curvatures calculated on the images using Avizo Software. They concluded, in particular, that higher image resolution was required as significant curvature errors were resulting from inadequate segmentation of small features.Following this work, Armstrong et al. (2012b) evaluated the limitations and advantages of measuring interfacial curvatures from X-ray microtomography data by comparing two approaches applied to idea spheres: the first approach measures curvature on triangular surfaces generated at interfacial regions, as described in Armstrong et al. (2012a), the second approach measures curvature directly from an image intensity gradient. The results showed that there is an optimal amount of smoothing with either approach and, in general, the surface-based approach gave the best results.Andrew et al. (2014b) then applied the method described by Armstrong et al. (2012a) to calculate interfacial curvature of water and supercritical $\mathrm{CO}_{2}\left(\mathrm{scCO}_{2}\right)\left(50^{\circ} \mathrm{C}\right.$ and $\left.10 \mathrm{MPa}\right)$ in a Ketton limestone sample using lab-based microtomography images with a pixel size of $3.5 \mu \mathrm{m}$. The authors reported that curvature distributions for a single ganglion present a single well-defined peak, representing a single capillary pressure across the entire $\mathrm{CO}_{2}$-brine interface. They also related capillary pressure measurements to local pore space topography and showed that capillary pressure was inversely proportional to the radius of the largest restriction surrounding the ganglion. In a recent publication aiming at identifying individual dynamic drainage events at the pore-scale using fast synchrotronbased microtomography images of $\mathrm{scCO}_{2}$ /brine in the same Kettonlimestone with a voxel size of $3.64 \mu \mathrm{m}$, Andrew et al. (2015) extended the pore-scale curvature measurement technique in order to be able to measure the smaller curvatures resulting from higher drainage capillary pressures. In particular they presented a method to select terminal 
1 menisci from the entire $\mathrm{CO}_{2}$ ganglia interfaces using curvature anisotropy and compute

2 the interfacial curvature using only these selected regions.

The Ostwald ripening process is driven by differences in capillary pressure, and consequently interfacial curvature, between ganglia. The study of the potential for Ostwald Ripening therefore requires accurate methods for measuring the interfacial curvature of an individual ganglia and its associated uncertainty in a variety of relevant rock types. The aim of the present study is to develop reliable methods for estimating the pore-scale capillary pressure of individual residually-trapped gas ganglia for different rock types, especially sandstones, and using higher resolution imagesin comparison to the previous studies by Armstrong et al. (2102a, 2012b) and Andrew et al. (2014b, 2015). Measurements are made on air ganglia trapped during gravitationally induced imbibition. Particular attention is given to the effect of image resolution on the precision of interfacial curvature calculations.A multi-scale synchrotron-based X-ray microtomography datasetof residually-trapped gas was therefore acquired in sintered glass beads and two sandstone samples (Boise and Fontainebleau) with voxel sizes varying from 0.64 to $4.44 \mu$ m.A method to estimate the interfacial curvaturewas developed based on this dataset and is presented, together with a sensitivity analysis of the method to parameters such as the degree of smoothing or the number of neighbor voxels used for the calculation. For each acquired image the non-wetting (air) and wetting (brine) phases were identified, as well as the interfaces they share both with each other and also with the solid surface, and the connectivity and size of the trapped gas were quantified. The curvature method was then applied to the different sub-volumes chosen for analysis. The distribution of curvature values, the mean value, and associated uncertaintyis presented for each disconnected air ganglion.Sub-volumes of the rock are then analyzed to determine the distribution of capillary pressures among the trapped ganglia; in particular, whether there is a statistically significant difference in the capillary pressures of the ganglia trapped in the sub-volume. A detailed analysis of the impact of image resolution and interface identification on curvature estimates is also reported.

The key point to assess the potential for Ostwald ripening in the investigated pore structures is to determine if neighbor gas ganglia have significantly different capillary pressures or not. Therefore a part of this work also consists in investigating the accuracy of the method proposed in the following to calculate capillary pressure using microtomographic images.

\section{Materials and methods}

\subsection{Rock samples}

The experiments were conducted on cylindrical cores of about $6 \mathrm{~mm}$ diameter from three different types of samples: sintered glass-beads, Boise sandstone and Fontainebleau sandstone. The sandstones samples were cored from larger blocks while the glass bead sample was sintered in a graphite mold. The samples were selected for their significant

46 differences in porosity and pore network morphology, as can be seen in Fig. 1. All of the 
1 samples are assumed to be strongly water-wet. The glass beads sample is composed of 2 soda lime beads of diameters ranging from 250 to $400 \mu \mathrm{m}$ and presents the highest 3 porosity and pore size. Although the focus of our study is on estimating capillary pressure 4 distribution in sandstones, the glass beads sample was chosen to develop the curvature 5 calculation method as large interfaces between the two fluids are expected. The Boise and 6 Fontainebleau samples are quarry sandstones from Boise, Idaho (USA) and the Paris

7 Basin (France) respectively. Fontainebleau sandstone is composed of well-sorted quartz 8 grains only (Bourbie and Zinszner, 1985) whereas Boise sandstone contains a significant 9 fraction of feldspar, mica, and clay materials (Zimmerman, 1984). Helium pycnometry 10 porosity measurements, $\phi_{H e}$, were conducted on samples extracted from the same blocks in which the samples used in the experiments were cored. The respective values of porosity measured for the glass-beads, Boise and Fontainebleau samples are 0.40, 0.28 and 0.10 . Mercury injection capillary pressure analysis (MICP) was also performed and the pore-throat diameter distributions are shown in Fig. 1. The corresponding mean diameters $d_{H g}$ are $101 \mu \mathrm{m}, 31 \mu \mathrm{m}$ and $14 \mu \mathrm{m}$ for the Glass beads, Boise and Fontainebleau samples, respectively.

\subsection{Experimental set-up and protocol}

Gravity-driven imbibition of water into an air-filled rock sample was used to create a residually trapped air phase. The samples were wrapped in a heat-shrink PTFE tube and mounted vertically on the rotating stage in the beamline hutch, as displayed in Fig. 2. The inlet and outlet, both wrapped together with the sample to assure fluid flow through the core, were connected to flexible tubing allowing rotation during scanning. Two valves were placed at the inlet and the outlet side in order to isolate the sample. The inlet tubing was also connected to a small reservoir located at an upper height so that gravity-driven imbibition could be performed: a solution of deionized water and $0.7 \mathrm{~mol} / \mathrm{L}$ potassium iodide, serving as a contrast agent, was poured in the reservoir and could then flow at room pressure and temperature through the dry sample by gravity leaving behind a fraction of trapped air. Both valves were closed after brine came out of the outlet valve and the system was left immobile 30 minutes to reach equilibrium before scanning.

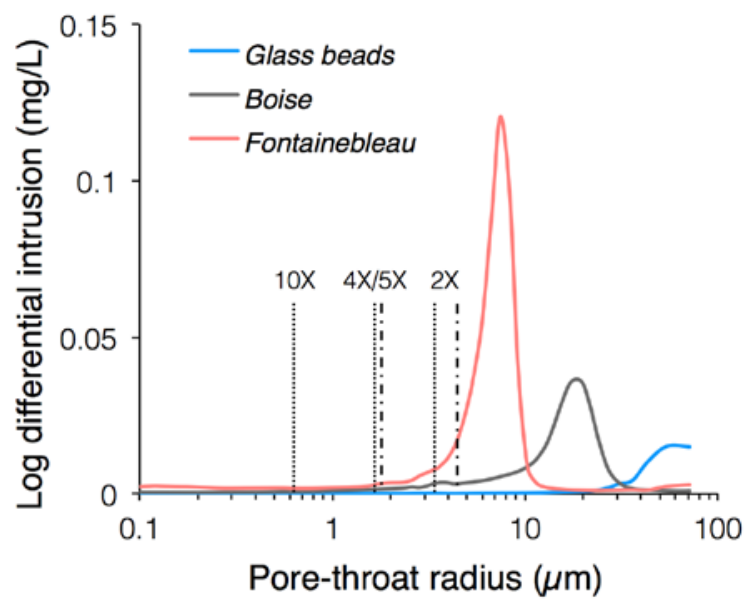


Fig. 1.Pore-throat size distribution obtained by MICP for the Glass beads (blue line), Boise sandstone (grey line) and Fontainebleau sandstone (pink line) samples presented as the differential intrusion. The voxel sizes for the different image acquisitions $(2 \mathrm{X}-3.28 \mu \mathrm{m}$ for the Glass beads and Fontainebleau samples, and $4.44 \mu \mathrm{m}$ for Boise sample / $4 \mathrm{X}-1.62 \mu \mathrm{m}$ for the Glass beads and Fontainebleau samples and $5 X-1.8 \mu \mathrm{m}$ for Boise sample / 10X $-0.62 \mu \mathrm{m}$ ) are displayed with dotted and dashed vertical lines.
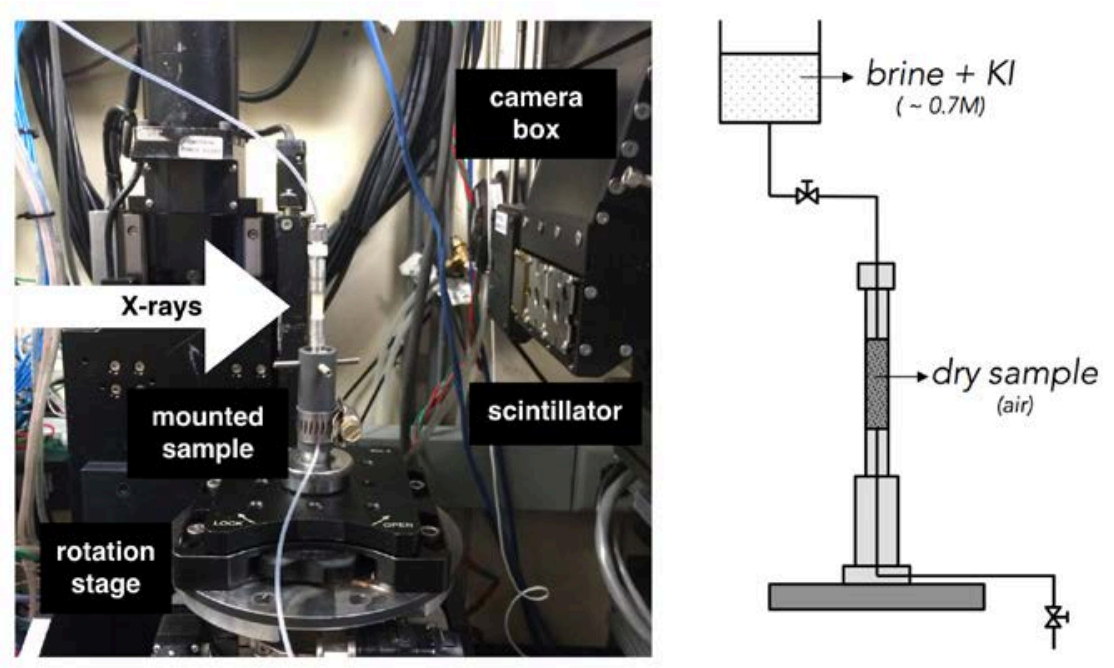

Fig. 2. Photograph (left) and graph (right) presenting the experimental set-up at the microtomographybeam line 8.3.2 of the Advanced Light Source, LBNL.

\subsection{Data acquisition}

The dataset was acquired at the beamline(BL) 8.3.2. ofthe Advanced Light Source (Lawrence Berkeley National Laboratory). Cross-sections through each imaged volume are displayed in Fig.3.In each case, a baseline scan of the dry sample was first acquired, then multiple scans at different resolutions were taken after the imbibition process. The entire dataset was acquired using two different optics configuration, leading to slightly different resulting voxel sizes for the Glass beads and Fontainebleau sandstone samples and for the Boise sandstone sample, as detailed below.

\section{Glass beads and Fontainebleau sandstone}

For both samples, a set of 2049 projections was acquired using a PCO.Edgecamera withan Optique Peter system; $2 \mathrm{X}(3.28 \mu \mathrm{m}), 4 \mathrm{X}(1.62 \mu \mathrm{m})$ and 10X $(0.64 \mu \mathrm{m})$ objectives were used as well as a multilayer monochromator set to $25 \mathrm{keV}$. The following exposure times were selected: $450 \mathrm{~ms}, 1200 \mathrm{~ms}$ and $1500 \mathrm{~ms}$ for the Glass beads 2X, 4X and 10X scans respectively; $475 \mathrm{~ms}$ and $1500 \mathrm{~ms}$ for the Fontainebleau $2 \mathrm{X}$ and $4 \mathrm{X}-10 \mathrm{X}$ scans respectively.

\section{Boise sandstone}

A set of 1441 projections was acquired using a PCO.4000 camera with normal optics 2X (4.44 $\mu \mathrm{m}$ voxel size) and $5 \mathrm{X}(1.80 \mu \mathrm{m}$ voxel size) atan energyof $32 \mathrm{keV}$. Exposure times of 800 msand 1000 mswere selected for the $2 \mathrm{X}$ and $5 \mathrm{X}$ scans respectively. 
The reconstruction of the volumes was performed using two different procedures, depending on the contrast needed in the datasets: i) a standard filtered back-projection, using a Shepp-Logan filter (Kak and Slaney, 1987) applied to the flat-field corrected projections, ii) a single-distance phase retrieval algorithm on the projections which improves the contrast among the different phases and reduces phase contrast artifacts. The algorithm presented by Paganin et al. (2002) and implemented in the ANKAphase software package (Weitkamp et al., 2011) was chosen for phase retrieval. The reconstruction was then performed using a conventional filtered back-projection algorithm with the Octopus software (Dierick et al., 2004).

The voxels are coded in terms of grey levels depending on the X-ray beam attenuation. The solid matrix appears in light grey, the brine in medium grey and the air in dark grey (Fig. 3).

\subsection{Image analysis}

Once the 3D volume is reconstructed, a sequenceof post-processing steps is required in order to quantify the fluid phase distribution, connectivity, cluster size, pore diameter or interfacial curvature. The successive steps are detailed belowand illustrated in Fig. $\mathbf{4}$ on a cropped volume of Boise sandstone BS-5X (voxel size of $1.80 \mu \mathrm{m}$ ). The image processing was conducted using Fiji, Avizo Fire 9 and MATLAB programs.

\subsubsection{Segmentation, connectivity and size}

All segmentations were performed on the raw reconstructed scans directlydue to the good qualityof the imaging process, except for BS-2X data (Boise sandstone, voxel size of 4.44 $\mu \mathrm{m}$ ) for which an edge-preserving noise reduction filter such as bilateral filter (Tomasi and Maduchi, 1998) was first applied first in order to reduce the noise. The segmentation of the three different phases, solid, brine, and gas, was carried out via visual inspection of the datasets and graylevel histogram using Fiji package. The brine segment was cleaned via a conventional procedure including median filtering and/or binary morphological operators, combined with masking (i.e. a Boolean AND operator) with the original segmented dataset. This procedure allows recovering the finer details of the objects erased by the structuring element shape and size used in the noise-reducing procedures. This approach is especially useful when dealing with binary datasets, where any filtering can significantly affect the morphology of the objects, and in our specific case it allowed more precise borders, as if segmented directly from the original unfiltered dataset, and especially correct solid-gas interfaces.Examples of 2D raw and segmented images are presented for the glass beads (Fig.4.1 and 2), the Fontainebleau sandstone (Fig.4.3 and 4) and the Boise sandstone (Fig.4.a and $\mathbf{b}$ )samples. The entire image processing workflow is displayed for the latter sub-volume (Fig.4.a to h).Each smaller sub-volume investigated was re-segmented using the same method than for the larger volumes for 44 more accurate results. The number of voxels belonging to the pore phase $V_{p}$ and 45 belonging to the air phase $V_{\text {air }}$ are computed and since the entire number of voxels 46 composing the analyzed rock volume $V_{\text {tot }}$ is also known, the total porosity $\phi_{\mu C T}$ and air 
1 saturation $S_{n w}$ can be calculated as $V_{p} / V_{\text {tot }}$ and $V_{\text {air }} / V_{p}$ respectively. The connectivity of 2 both fluid phases, air and brine, is then quantified by analyzing the data in 3D (Fig 4.c 3 and d.). Each disconnected cluster is identified and re-labeled and its volume is 4 computed. In addition, the equivalent diameter distribution of the air phase, brine phase 5 and pore space (air and brine grouped as a unique phase) was computed by generating 6 distance maps and recording the diameter of maximum inscribed spheres.Both 7 connectivity and equivalent diameter analysis were conducted using Avizo Fire 9 8 Software.
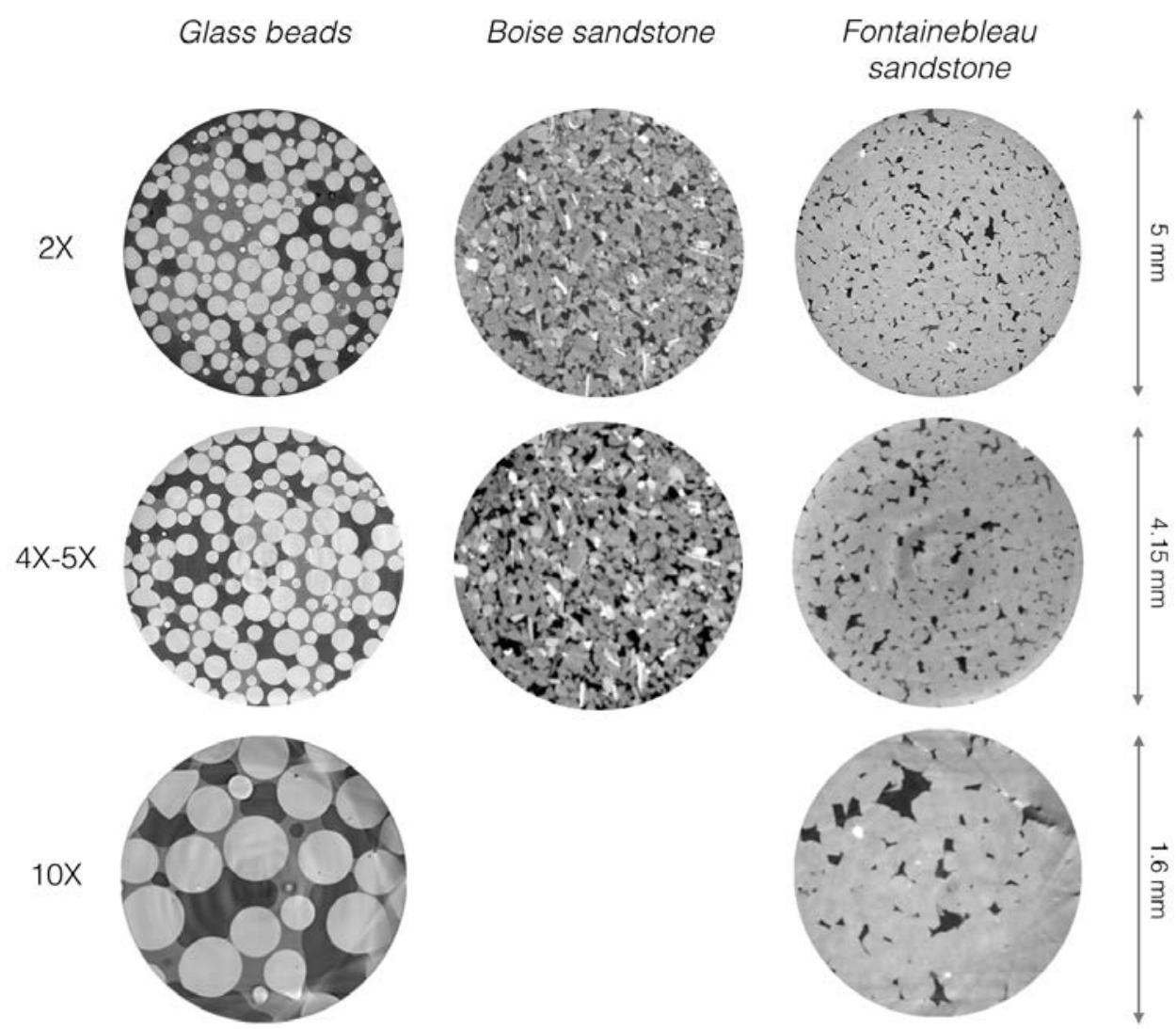

Fig. 3.Two-dimensional cross sections through the 3D reconstructed volumes for the Glass beads, Boise sandstone and Fontainebleau sandstone imaged with different magnification resulting in multiple resolutions: $2 \mathrm{X}-4 \mathrm{X}-10 \mathrm{X}$, respective voxel sizes of $3.28 \mu \mathrm{m}-1.62 \mu \mathrm{m}-0.64 \mu \mathrm{m}$, for the glass beads and Fontainebleau sandstone samples and $2 X-5 X$, respective voxel sizes of $4.44 \mu \mathrm{m}-1.8 \mu \mathrm{m}$, 

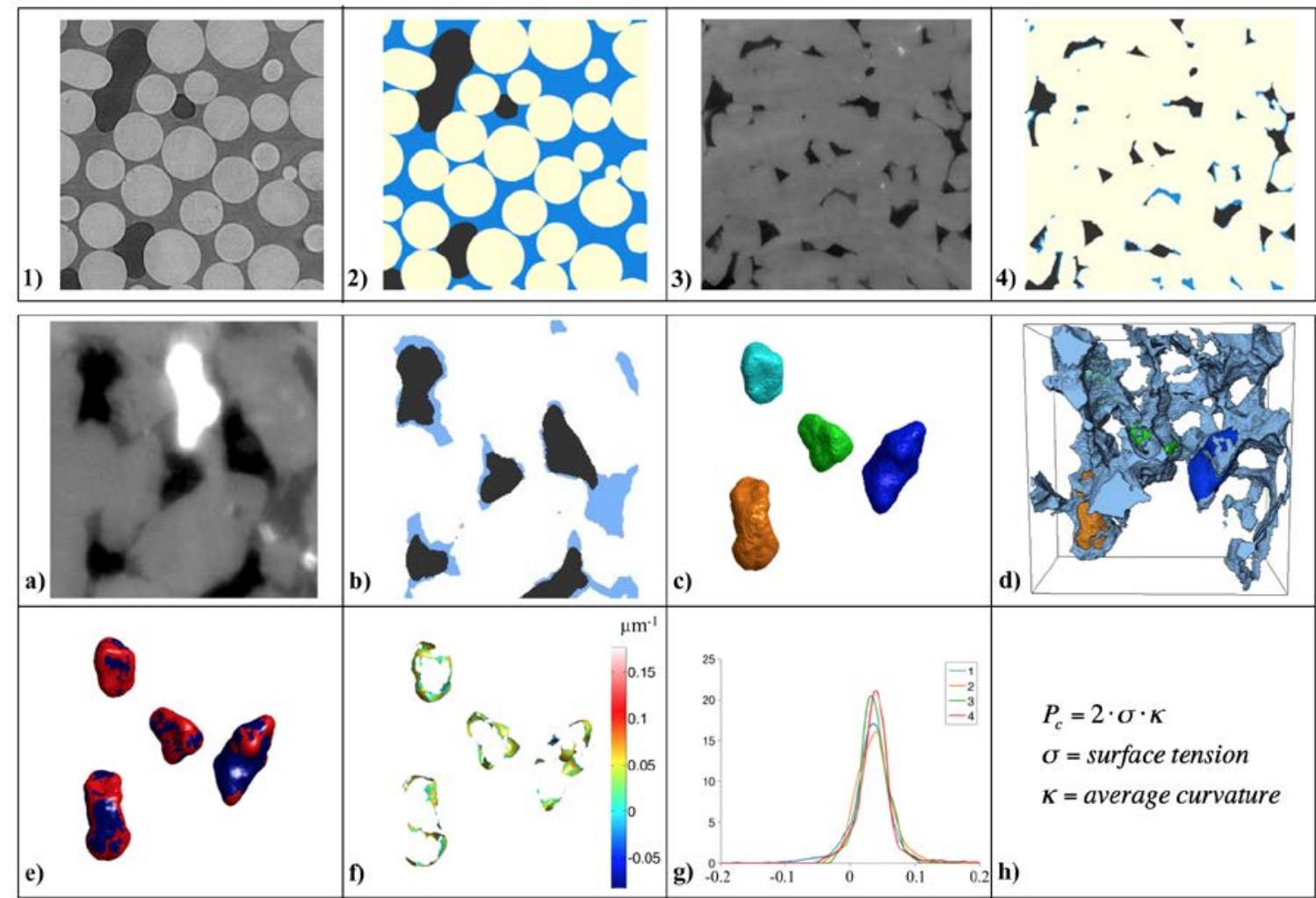

Fig. 4.Examples of 2D raw image after reconstruction and the corresponding 2D segmented image of the glass beads sample (1) and 2) respectively) and the Fontainebleau sandstone sample (3) and 4) respectively); Three phases are identified: the solid matrix (yellow), the air (black) and the brine (blue).The entire image processing workflowis then presented for a cropped sub-volume of Boise sandstone $5 X(290 * 290 * 140$ voxels with a voxel size of $1.80 \mu \mathrm{m})$. a) $2 \mathrm{D}$ raw image. b) 2D segmented image. c) 3D rendering of the separated air clusters, or ganglia. d) 3D rendering of the air ganglia together with the brine phase (light blue). e) Visualization of the interfaces with the brine phase presented by each gas ganglion. f)The mean curvature is calculated for each point of the air/brine interface. g) The curvature histograms are extracted and a mean curvature value can be calculated for each gas ganglion and for the entire investigated volume. h) The capillary pressure is calculated using the computed mean curvature and the appropriate surface tension value.

\subsubsection{Interfacial curvature}

This subsection describes the workflow for the method developed to compute interfacial curvature of gas clusters using the segmented micro-CT images, where voxels belong to one of the three identified phases (rock, brine or gas). The main steps consist offinding and meshing the surface of the gas phase; restricting it to the interface shared with the brine phase; smoothing the resulting mesh; and calculatingthe corresponding curvature, as detailed below.All steps are performed by a in-house MATLAB code specifically developed for this study.

Meshing the interface 
The surfaces of the gas and brine phases are identified by using the MATLAB (MathWorks) function isosurface, an implementation of the Marching Cubes algorithm, leading to a trigonal mesh representing the surface of the gas phase together with a list of vertices that belongs to both gas and brine surfaces, which describe the interface under consideration (Fig. 4.e).In order to deal with potential edge effects at the line of contact where there is a discontinuity in curvature, the in-house code developed by the authors deletes the vertices that belong to the rock/gas interfaces from the mesh before applying smoothing and computing the curvature. This in in contrast with previous studies where a commercial software is used and the user must wait for the end result to heuristically prune unrealistic curvature values (Andrew et al., 2015).

Smoothing the surface

The mesh resulting from the previous steps is smoothed using animplicit fairing method of the type described in Desbrun et al. (1999). This smoothing method attenuates noise in the mesh through a diffusion process: a linear approximation of the mesh Laplacian is computed and used (via implicit integration in time of a heat diffusion type equation) to disperse small disturbances and smooth high frequencies while keeping the main shape intact.Specifically, we consider a mesh $X$ with $m$ vertices $x_{i}, i=1 \cdots m$ and integrate the following equation over time:

$$
\frac{\partial X}{\partial t}=\lambda L(X)(1)
$$

where $L(X)$ is the mesh Laplacian and $\lambda$ is a parameter (taken to be 1 in our application). More details on Laplacian mesh processing can be found in Sorkine (2006).An explicit Euler scheme is used to integrate Equation (1):

$$
X^{n+1}=(I+\lambda \delta t L) X^{n}
$$

We call $T_{\max }$ the time for which the mesh is smoothed.It means that Equation (2) will be used $\left[T_{\max } / \delta t\right]$ times.Fig. 5 shows an example of the impact of smoothing, $T_{\max }$ ranging from 0 (raw mesh) to 6 (18 iterations of the heat diffusion procedure with a time step $\delta t$ of 0.3 ), for a single air ganglia isolated from (a) the glass beads sample imaged with a voxel size of $0.64 \mu \mathrm{m}$ and (b) the Boise sandstone sample imaged with a voxel size of $1.8 \mu \mathrm{m}$. The curvature estimates rapidly converge once a small amount of smoothing is applied, as previously reported by Andrew et al. (2014a). We chose a value of $T_{\max }=5$ and $\delta t=0.3$ for the following.

Estimating the curvature of a mesh

For any point $P$ on a surface, we can define the unit normal vector $n(P)$. The derivative of $n$ at $P$ defines the shape operator whose eigenvectors and eigenvalues are the principal directions and principal curvatures (Federer, 1959). If $\kappa_{1}(P)$ and $\kappa_{2}(P)$ denote the principal curvatures at point $P$, the mean curvature is $\kappa(P)=\left(\kappa_{1}(P)+\kappa_{2}(P)\right) / 2$ and the Gaussian curvature is $\Gamma(P)=\kappa_{1}(P) \cdot \kappa_{2}(P)$.In this paper the term curvature is generically used to denote the mean curvature $\kappa(P)$ at point $P$.A classic approach to compute the curvature of a mesh is to locally approximate it using quadric surfaces, 43 Steiner and Morvan (2003) consists of redefiningcurvature in the context of normal cycle 44 theory so that the definition now holds for polygonal surfaces. This work builds on the 
1 observation that the curvature measures of a smooth surface can be obtained from an 2 object associated to the surface called the normal cycle of the surface and that the 3 definition of the normal cycle of a surface has a unique natural extension to the case of a 4 polyhedral surface (a mesh). G. Peyreimplemented an algorithm in MATLAB as well as 5 other useful graph theory utilities that are used in this work for curvature calculations 6 (Peyre, 2007).In the end, a mean curvature estimate is obtained for each vertex of the 7 air/brine interface (Fig. 4.f).

The method involves a parameter corresponding to the number of neighbors, $N_{\text {neig hbors }}$, 10 over which the curvature tensor is averaged when it is calculated at each vertex. Fig. 5

11 shows the impact of averaging related to the number of neighbors chosen, $N_{\text {neig hbors }}$ 12 ranging from 3 to 60 , for the single air ganglia isolated from (a) the glass beads sample 13 imaged with a voxel size of $0.64 \mu \mathrm{m}$ and (b) the Boise sandstone sample imaged with a 14 voxel size of $1.8 \mu \mathrm{m}$. For both cases, the graphs suggest that the curvature estimates are 15 similar when selecting a higher number of neighbors for the calculations, the distribution 16 functions becoming however less spread out when averaging on more neighbors, as 17 expected. In order to stay relatively close to the real data we chose to $N_{\text {neig hbors }}=7$ in 18 the following.

20 For several isolated ganglia we also performed curvature calculations using an 21 implementation of the quadric fitting algorithm in MATLAB (Kroon, 2011) and using the 22 corresponding implementation in the Avizo Fire package (FEI). The three calculations 23 lead to similar mean curvature values, especially once some smoothing was applied to the 24 mesh. We decided to use our own developed code for more flexibility and we chose to 25 use the normal cycle algorithm due to the fact that the quadric fitting method may be 26 prone toinstability, as the algorithm requires inverting matrices that can be ill27 conditioned. 

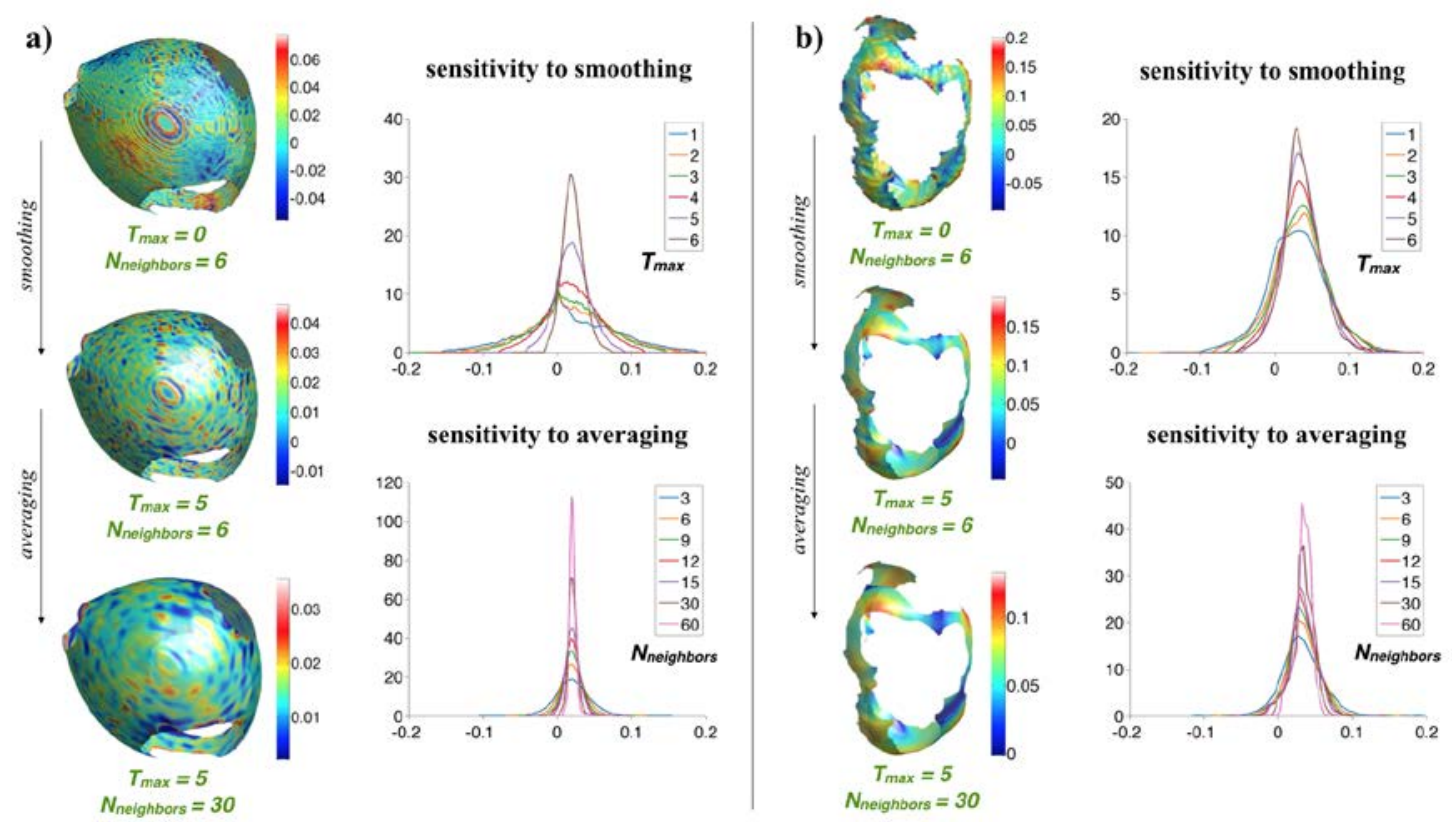

Fig.5.Sensitivity analysis performed on a single air ganglia isolated froma)the glass beads sample imaged with a voxel size of $0.64 \mu \mathrm{m}$ and $\mathbf{b}$ ) and from the Boise sample images with a voxel size of $1.8 \mu \mathrm{m}$ : effect of smoothing $\left(T_{\max }\right)$ and averaging $\left(N_{\text {neig hbors }}\right)$ on the mean curvature calculated using the normal cycle method.

9 The curvature estimates obtained for the entire air/brine interface can be investigated for 10 each disconnected gas ganglion. Curvature distributions for each ganglion are plotted as 11 probability distribution functions (Fig. 4.g) and an average mean curvature $\kappa$ is 12 calculated for each ganglion. The corresponding averagemean capillary pressure $P_{c}$ is then estimated assuming that Laplace's law, $P_{c}=2 \cdot \sigma \cdot \kappa$ (Fig. 4.h), is valid for the unsupported interface of the gas ganglia and using an interfacial tension $\sigma$ for air and water of $72 \mathrm{mN} . \mathrm{m}^{-1}$ (Vargaftik et al., 1983).

\section{Fontainebleau sandstone}

A slightly different procedure was applied to the Fontainebleau sandstone dataset where, due to the high resolution of the images and nature of the pore-space, brine films are detected between the ganglia and rock surface. In these regions, the gangliaare supported by the rock, not the interfacial tension between the gas and the liquid and therefore these flat interfaces should be removed forcurvature calculations. Identifying the vertices that belong to the thin films is however not trivial. We first handled this issue by deleting the connected components of the mesh that have negative curvature values and represent a large number of voxels.

28 Confidence intervals were calculated using the classic expression for the Standard Error of the mean $S E=S D / \sqrt{n}$, where $S D$ is the sample standard deviation and $n$ is the number of samples. Assuming normal distributions, the true mean of the distribution we 
1 are sampling from has a 95\% probability to be within1.96 $\cdot S E$ away from the mean.

2 When applied to a single ganglion, these confidence intervals give a measure of how well

3 the capillary pressure of an individual disconnected ganglion can be estimated.For a

4 single ganglion the following nomenclature is used: the mean curvature, which is the

5 average of all curvature values calculated for each points of the interface, is noted $\kappa$ and 6 the standard deviation and error for the ganglion are respectively noted $S D_{g}$ and $S E_{g}$. 7 Average values for the entire population of ganglia are indicated by $\langle\cdot\rangle$, where $\langle X\rangle=$ $8\left(\sum_{N \text { ganglia }} X\right) / N$ ganglia. The average ganglion standard deviation and error for the 9 population of ganglia are therefore noted $\left\langle S D_{g}\right\rangle$ and $\left\langle S E_{g}\right\rangle$ respectively, and $\langle k\rangle$ and $\left\langle P_{c}\right\rangle$ 10 refer to the average mean curvature and capillary pressure for a given sample. Finally the 11 standard deviations of the ganglia mean curvature and ganglia capillary pressure for the 12 entire ganglia population of a sample are noted $S D_{K}$ and $S D_{P C}$ respectively.

\section{Results}

The first part of this section presents the results for the analysis of fluid phase distribution and morphology for the three investigated rock samples, with a presentation of the air and brine distribution, connectivity and equivalent diameter, and air ganglia size. This first subsection aims at characterizing the three different pore structures and their corresponding fluid phase distribution and morphology in relation with the image resolution in order to determine the appropriate resolution and volume required for each rock type for an accurate identification of representative air/brine interfaces.

The second part of this section first presents curvature calculations results for single ganglia, with a focus on the impact of image resolution and interface identification on how well the capillary pressure in one ganglion can be estimated. The curvature and capillary pressure calculationsfor the population of ganglia presented by all the subsamples analyzed are then presented for each rock type.

\subsection{Fluid phase distribution and morphology}

For each dataset available the results are presented for all the sub-samples on which the detailed analysis were performed (Table 1). Porosity $\phi_{\mu C T}$ and air saturation $S_{n w}$ were also computed on larger volumes to assess the representative character of the subvolumes. The results are available in supplementary materialTable $\mathbf{S 1 .}$

\begin{tabular}{|c|c|c|c|c|c|c|c|}
\hline $\begin{array}{l}\text { Rock } \\
\text { sample }\end{array}$ & $\begin{array}{c}\mu \mathrm{CT} \\
\text { images }\end{array}$ & $\begin{array}{c}\text { Voxel size } \\
(\mu \mathrm{m})\end{array}$ & $\underset{\left(\mathrm{mm}^{3}\right)}{\mathbf{V}}$ & $\begin{array}{c}\phi_{\mu c T} \\
(-)\end{array}$ & $\begin{array}{c}S_{n w} \\
(-)\end{array}$ & $\begin{array}{c}N_{\text {tot }} \\
\text { ganglia }\end{array}$ & $\begin{array}{c}N \\
\text { ganglia }\end{array}$ \\
\hline \multirow{2}{*}{ Glass beads } & GB-2X* & 3.28 & 8.3 & 0.36 & 0.19 & 5 & 5 \\
\hline & GB-4X* & 1.62 & 1 & 0.37 & 0.81 & 3 & 3 \\
\hline \multirow{4}{*}{ Boise } & BS-2X' & 4.44 & 1.3 & 0.19 & 0.60 & 90 & 73 \\
\hline & BS-5X ${ }^{+}$ & 1.80 & 1.3 & 0.18 & 0.66 & 122 & 90 \\
\hline & BS-5X* & 1.80 & 1 & 0.25 & 0.40 & 114 & 102 \\
\hline & BS- $5 X^{\circ}$ & 1.80 & 0.48 & 0.29 & 0.53 & 49 & 38 \\
\hline \multirow{2}{*}{ Fontainebleau } & FS-4X* & 1.62 & 1 & 0.07 & 0.72 & 157 & 107 \\
\hline & FS-10X* & 0.64 & 0.05 & 0.06 & 0.75 & 26 & 20 \\
\hline
\end{tabular}


Table 1. Characteristics of the sub-samples investigated using multi-scale X-ray microtomography: name of the sub-sample, voxel size (length of the side of the cube forming the voxel $[\mu \mathrm{m}]$ ), volume $\left[\mathrm{mm}^{3}\right]$, computed porosity $\phi_{\mu C T}$ and air saturation $S_{n w}$, number of separated air ganglia $N_{\text {tot }}$ ganglia and number of these ganglia presenting an interface with the brine phase large enough for the interfacial curvature analysis $N$ ganglia.

\subsubsection{Air and brine distribution and connectivity}

For each rock type the fluid phase distribution was investigated by analyzing a same subvolumes of $1 \mathrm{~mm}^{3}$ imaged with comparable voxel size $(1.62 \mu \mathrm{m}$ for the Glass beads and Fontainebleau sub-samples, respectively GB-4X* and FS-4X*; and $1.80 \mu \mathrm{m}$ for the Boise sub-sample BS-5X*). The results are displayed in Fig. 6. For each rock type, the results were compared with sub-samples imaged with lower and/or higher resolution.

The glass beads sub-sample has the highest porosity (0.37) and air saturation (0.81) and presentsthe largest interfaces between the two fluid phases (Fig. 6.a). The residual air phase forms a large connected cluster representing 98\% of the air phase (Fig. 6.b), and the brine phase is also well connected with somelocally disconnected brine identified as pendular rings between beads (Fig. 6.c), as previously reported by Armstrong et al. (2012a). The analysis of a larger sub-volume of the glass beads sample imaged with a lower resolution shows that the sub-sampledisplays a similar porosity (Table 1) and a much lower air saturation, which however corresponds to the value computed on the large volume with the same resolution (Table S1). The characteristics of the fluid phases are very similar between the two sub-samples, with one large well-connected cluster spanning through the whole volume (Fig. 8.a) and large interfaces with a well-connected brine phase (Fig. 9.b). Considering the fluid configuration, the image acquired with the highest resolution (GB-10X) implying a much smaller volume sampled, was not analyzed for curvature calculation purpose.

The sandstone samples have very different pore space size distributions and topologies in comparison to the glass beads sample, and have distinct fluid phase distributions and morphologies. Looking first at the $1 \mathrm{~mm}^{3}$-cubes, the results show that although the two sub-samples exhibit different values of porosity $(0.25$ for Boise and 0.07 for Fontainebleau) and air saturation ( 0.40 for Boise and 0.72 for Fontainebleau), they both present a residual air phase that consists of a large number of disconnected air ganglia with a high fraction of small size ganglia and few larger ones, as displayed in Fig. 6.e and Fig. 6.f for Boise and Fontainebleau respectively. In the case of the Boise sub-sample, the air phase presents a noticeably large fraction of interfaces with the brine phase (Fig. 6.b) and the brine phase forms a large well-connected cluster spanning throughout the subvolume, with few small-size disconnected clusters (Fig. 6.h). Fig. 6.c shows that there are fewer interfaces between the air and brine phases for the Fontainebleau $1 \mathrm{~mm}^{3}$-cube and that they consist of much smaller features. One should note the high air saturation for this sample. With a voxel size of $1.62 \mu \mathrm{m}$, the brine phase appears as very poorly connected, as it consists of a high number of small size disconnected clusters of brine (Fig. 6.i). 

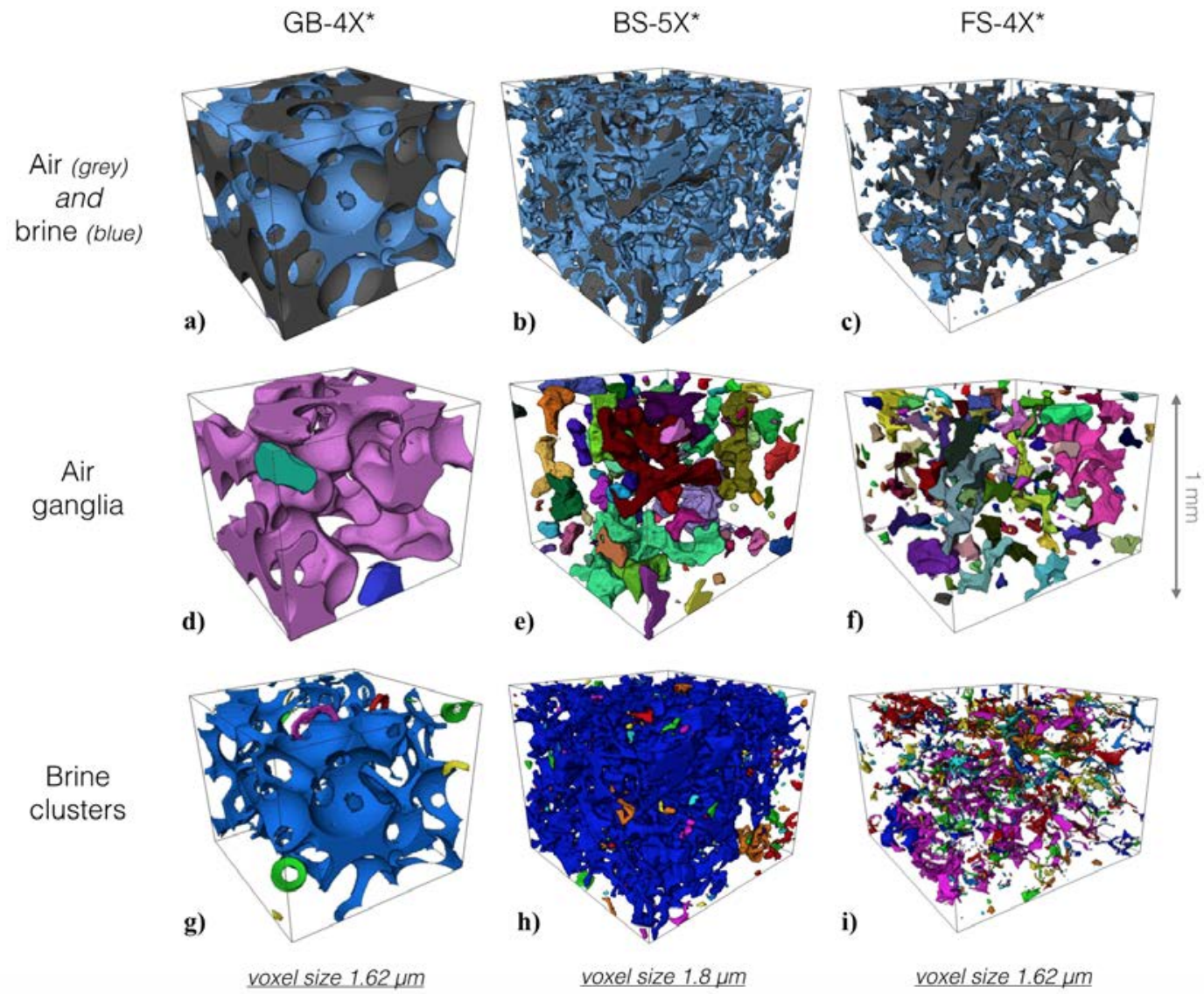

voxel size $1.62 \mu \mathrm{m}$

Fig. 6.3D rendering of fluid phase distribution and connectivity in $1 \mathrm{~mm}^{3}$ sub-volumes of the three rock samples imaged with similar resolution and named GB-4X*, BS-5X* and FS-4X* for the Glass beads, Boise sandstone and Fontainebleau sandstone sample, respectively. a), b) and c): air (dark grey) and brine (blue) phase distribution in the pore space. d), e) and f): disconnected air ganglia represented with different colors. g), h) and i) clusters formed by the brine phase. As for the air ganglia different clusters are displayed with different colors.

The analysis of a larger and a smaller sub-volume the Boise sample imaged with the

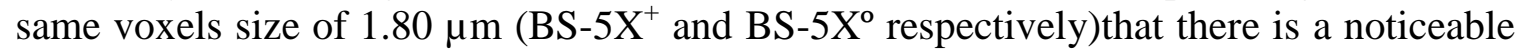
discrepancy between computed porosity and air saturation for each sub-volume, with porosity values ranging from 0.18 to 0.25 and air saturation values ranging from 0.40 to 0.66 (Table 1). However, the three sub-samples present very similar fluid phase distribution, with a high number of disconnected air ganglia (Fig. 10.e, $\mathbf{i}$ and $\mathbf{m}$ ) and well-identified interfaces with the brine phase (Fig.10.f, $\mathbf{j}$ and $\mathbf{n}$ ).A comparison with the lower resolution was also conducted by analyzing the exact same sub-volume of $1.3 \mathrm{~mm}^{3}$ imaged with a voxel size of $1.8 \mu \mathrm{m}\left(\mathrm{BS}-5 \mathrm{X}^{+}\right)$and a voxel size of $4.44 \mu \mathrm{m}\left(\mathrm{BS}-2 \mathrm{X}^{+}\right)$.The computed porosity values are very close and the air saturation computed on $\mathrm{BS}-2 \mathrm{X}^{+}$is lower than for BS-5X', as listed in Table 1. In general the large to medium size air clusters are identically identified for both sub-samples but smaller air ganglia are not identified for BS-2X+ (Fig. 10.a and e). The most difference comes from the identification of the air/brine interfaces. Although they appear localized at the same parts of the air ganglia, the interfaces are much smaller for $\mathrm{BS}-2 \mathrm{X}^{+}$(Fig. 10.b and f). 
2 Finally, a smaller sub-volume of the Fontainebleau sample imaged with the highest 3 resolution was also analyzed (FS-10X*). The porosity and air saturation computed on this 4 sub-sample are similar to the ones computed on the $1 \mathrm{~mm}^{3}$-cube imaged with the 5 intermediate resolution (Table 1).As for the Boise samples, the fluid phase distribution is 6 very similar between the two sub-samples with an air phase consisting in many 7 disconnected angular-shaped air ganglia (Fig. 11.a and e) presenting thin interfaces with 8 the brine phase (Fig. 11.b and $\mathbf{f}$ ). One can note that a high portion of the air/brine 9 interfaces consist in thin films between the air ganglia and the solid matrix. Due to the 10 small features presented by the brine phase and the interfaces with the trapped gas, the image acquired with the lower resolution (FS-2X) was not usedfor curvature calculations.

\subsubsection{Air and brine equivalent diameter}

The mean equivalent diameter presented by the air and brine phase, as well as by the entire pore-structure saturated with air and brine, were analyzed for the $1 \mathrm{~mm}^{3}$-cubes presented in the previous sub-section. The mean values are listed in Table 2 and the 18 distributions are displayed in Fig. 7.

19

\begin{tabular}{|c|c|c|c|c|c|}
\hline \multirow{2}{*}{$\begin{array}{c}\mu \mathrm{CT} \\
\text { images }\end{array}$} & \multirow{2}{*}{$\begin{array}{c}\text { Voxel size } \\
\qquad(\mu \mathrm{m})\end{array}$} & \multicolumn{3}{|c|}{ Mean equivalent diameter $(\mu \mathrm{m})$} & \multirow{2}{*}{$\begin{array}{c}\boldsymbol{d}_{\boldsymbol{H} \boldsymbol{q}} \\
(\mu \mathrm{m})\end{array}$} \\
\hline & & pore & air & brine & \\
\hline GB- $4 X^{*}$ & 1.62 & 147 & 148 & 87 & 101 \\
\hline BS-5X* & 1.80 & 62 & 68 & 43 & 31 \\
\hline FS- $4 X^{*}$ & 1.62 & 39 & 52 & 11 & 14 \\
\hline
\end{tabular}

Table 2. Mean equivalent diameter of the pore, air and brine phase computed on the $1 \mathrm{~mm}^{3}$ subvolumes of the glass beads (GB-4X*), Boise (BS-5X*) and Fontainebleau (FS-4X*) samples. The 24 mean pore throat diameter $d_{\mathrm{Hg}}$ estimated using MICP is reminded in the last column.

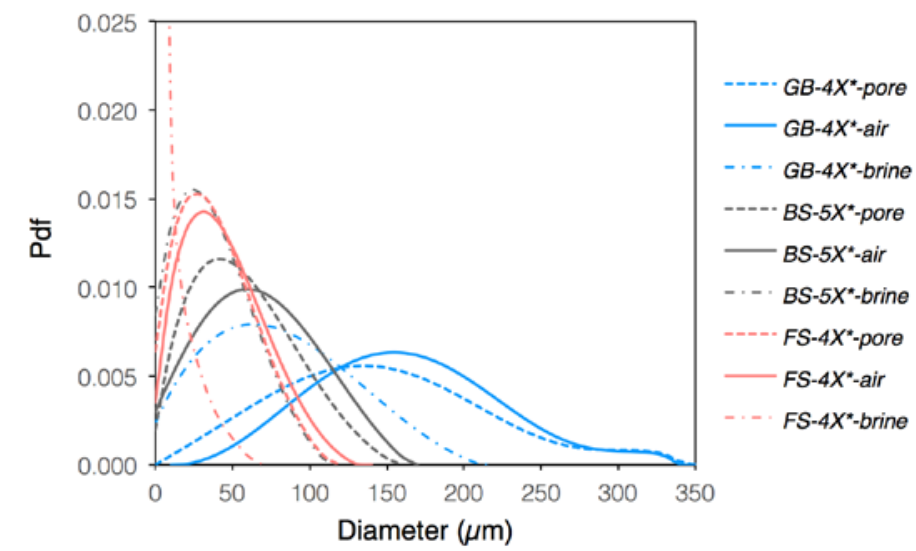

26 Fig. 7.Equivalent diameter distribution of the pores (dashed lines), air (solid lines) and brine (dashed-dotted lines) phase expressed as fitted probability density function pdf for the Glass beads sub-sample GB-4X* (blue lines), Boise sandstone sub-sample BS-5X* (grey lines) and Fontainebleau sub-sample FS-4X* (pink lines) of $1 \mathrm{~mm}^{3}$. 
1 The results shows that both the air and brine phaseof the Glass beads sample presents

2 large geometries and that the mean equivalent diameter of the air phase is similar as the 3 one of the pore space. For the Boise sample, the mean equivalent diameter of the phase 4 presenting the smallest features, the brine phase, is slightly higher than the mean pore5 throat diameter estimated with MICP $(31 \mu \mathrm{m})$ and corresponds to about 20 voxels. In 6 contrary, the mean diameter of the brine phase for the Fontainebleau sample is smaller 7 than the mean pore-throat diameter $(14 \mu \mathrm{m})$ and the distribution plot confirms that a 8 significant fraction of the brine phase is of a size smaller than the image resolution of the 94 X dataset.

\subsubsection{Residual air ganglia size}

For all the sandstone sub-samples, the air ganglia size (volume) and their distribution were analyzed. The results are displayed in Figure 8 and additional details are provided in supplementary Table S2. The $1 \mathrm{~mm}^{3}$-cube from the Boise sample (BS-5X*) contains 114 air ganglia (Table1) with a mean volume of $1.8 \mathrm{E}-4 \mathrm{~mm}^{3}$, equivalent to the volume of a sphere of about $70 \mu \mathrm{m}$ diameter. The largest ganglion represents $17.2 \%$ of the total air phase and the seven largest ganglia accounts for $50 \%$ of the air phase. As expected, for a same resolution, the number of identified disconnected clusters depends on the volume of the sub-sample analyzed (Table 1). However, the mean air ganglia volume is almost identical for the three sub-volumes BS-5X+, BS-5X* and BS-5X (Table S2) as is the air ganglia volume distribution (Fig. 8). When comparing an identical volume imaged with two different resolution (BS-2X $\mathrm{X}^{+}$and $\mathrm{BS}-5 \mathrm{X}^{+}$), the results shows that although fewer disconnected air ganglia are identified with the lower resolution, the mean air ganglia volume is in the same order of magnitude (Table S2) and the air ganglia volume distribution is almost identical (Fig. 8).

The $1 \mathrm{~mm}^{3}$-cube from the Fontainebleau sample (FS- $\left.4 X^{*}\right)$ has a larger number of air ganglia than the Boise sub-sample of same volume (Table 1): the air phase consists of 157 disconnected ganglia. The mean volume of these ganglia is $6.6 \mathrm{E}-5 \mathrm{~mm}^{3}$, which would be equivalent to a sphere of $50 \mu \mathrm{m}$ diameter, and is 2.7 times smaller than for BS$5 X^{*}$. The largest ganglion represents a smaller fraction of the total air phase (12.9\%) and also more ganglia are required to account for $50 \%$ of the air phase (Table S2, Fig. 8).When comparing with the highest resolution, less and one order of magnitude smaller size air ganglia are identified for FS-10X* than for FS- $4 X^{*}$ but it should be noted that in that case the total volume analyzed is also much smaller for FS-10X* $\left(0.05 \mathrm{~mm}^{3}\right)$ than for FS-4X* $\left(1 \mathrm{~mm}^{3}\right)$. 


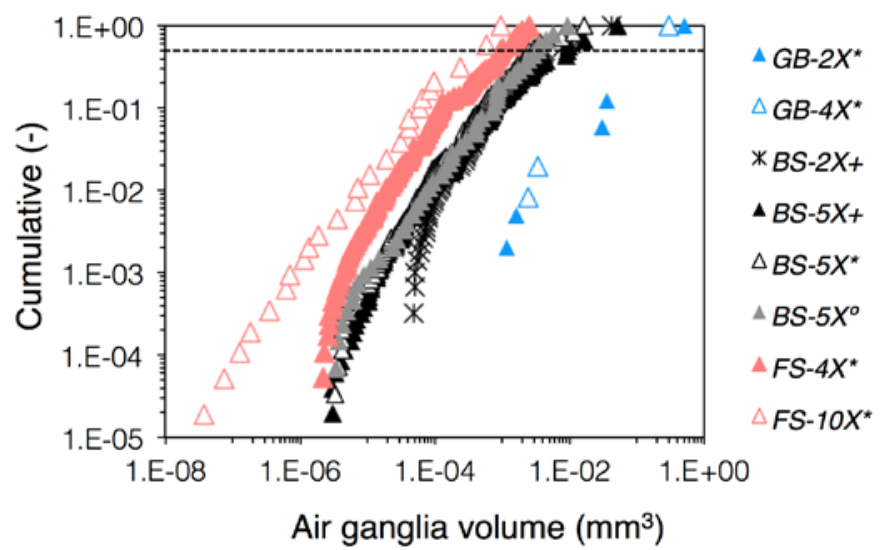

Fig. 8.Cumulative air ganglia volume. The dotted line indicates half of the air phase volume (cumulative of 0.5).The results are presented for the different sub-samples investigated for the Boise sample imaged with a voxel size of $4.44 \mu \mathrm{m}\left(\mathrm{BS}-2 \mathrm{X}^{+}\right)$and $1.8 \mu \mathrm{m}(\mathrm{BS}-5 \mathrm{X}+$, BS-5X* and BS-5X $\mathrm{X}^{\circ}$ - black and grey symbols, and for the Fontainebleau sample imaged with a voxel size of $1.62 \mu \mathrm{m}\left(\mathrm{FS}-4 \mathrm{X}^{*}\right)$ and $0.64 \mu \mathrm{m}\left(\mathrm{FS}-10 \mathrm{X}^{*}\right)$ - pink symbols.

\subsection{Interfacial curvature}

\subsubsection{Calculation of the capillary pressure in an individual ganglion}

Before investigating the capillary pressure of all the ganglia identified for each subvolume presented in the previous section, a first analysis of the impact of image resolution and interface identification on curvature calculations, hence capillary pressure estimates, was conducted on single isolated ganglia.

The effect of image resolution on the calculation of interfacial curvature was investigated by analyzing the same air ganglion that could be identified on two images of the same sample acquired with different image resolutions. The analysis was conducted on an isolated air ganglion for the glass beads sample imaged with a voxel size of $1.62 \mu \mathrm{m}$ and $0.64 \mu \mathrm{m}, \mathrm{GB}-4 \mathrm{X}$ and GB-10X respectively (Fig. 9.a), the Boise sample imaged with a voxel size of $4.44 \mu \mathrm{m}$ and $1.80 \mu \mathrm{m}, \mathrm{BS}-2 \mathrm{X}$ and BS-5X respectively (Fig. 9.b) and the Fontainebleau sample imaged with a voxel size of $1.62 \mu \mathrm{m}$ and $0.64 \mu \mathrm{m}$, FS-4X and FS10X respectively (Fig. 9.c). Details regarding the curvature calculations are given in Table 3.a. For the glass beads sample the isolated air bubble present similar characteristics with both resolutions: the shape and volume of the bubble is almost identical as is the interface with the brine phase and its curvature. The mean value $\kappa$ is $0.0219 \mu^{-1}$ for GB-4X and $0.0226 \mu^{-1}$ for GB-10X, leading to similar mean capillary pressure $P_{c}$ of 3,148 $\mathrm{Pa}$ and 3,260 $\mathrm{Pa}$ for GB-4X and GB-10X respectively. The standard errors are low and lead to $95 \%$ confidence intervals of $\pm 24 \mathrm{~Pa}$ and $\pm 12 \mathrm{~Pa}$ for the GB-4X and GB-10X bubble respectively.

The results differ in the case of the sandstone samples. For both the Boise and Fontainebleau samples, the air ganglia identified present some discrepancy although the 
cases one can note that the volume is lower with higher resolution. Fig 9.b and c also shows that the portion of the air surfaces that is shared with the brine phase is roughly 3 located on the same parts of the air ganglia. However, due to a very different number of 4 points representing the identified interfaces with the different image resolution (lower with bigger voxel sizes), the interface that remains after the image processing for the curvature calculation highly differs. For the Boise sample, the final mean value $\kappa$ is $0.0309 \mu^{-1}$ for BS-2X and $0.0483 \mu \mathrm{m}^{-1}$ for BS-5X, leading to capillary pressure $P_{c}$ of 4,450 $\mathrm{Pa}$ and 6,955 $\mathrm{Pa}$ for BS-2X and BS-5X ganglia respectively. The standards errors are higher then for the Glass beads ganglion. The corresponding 95\% confidence intervals in terms of capillary pressure are \pm 240 Paand $\pm 201 \mathrm{~Pa}$ for BS-2X and BS-5X respectively. For the Fontainebleau sample, there are not enough voxels left after processing to estimate the curvature of the FS-4X ganglion. The mean curvature calculated on the FS-10X ganglion is $0.124 \mu^{-1}$, which corresponds to a capillary pressure of $17,903 \mathrm{~Pa}$. For this ganglion the $95 \%$ confidence interval on the capillary calculation is $\pm 453 \mathrm{~Pa}$.$$
\text { a) }
$$

a) voxelsize
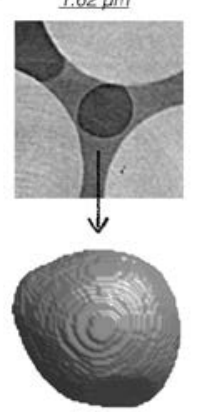

117.961 voxels $4.9^{*} 10^{-4} \mathrm{~mm}^{3}$

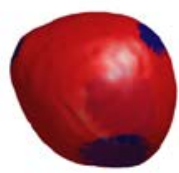

13,545 voxels $3.5^{*} 10^{-2} \mathrm{~mm}^{2}$

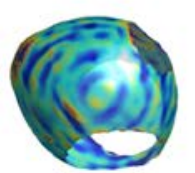

$0.022 \mu m^{-1}$

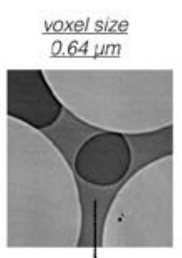

$\downarrow$

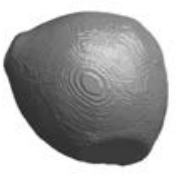

$1,814,138$ voxels $4.8^{*} 10^{-4} \mathrm{~mm}^{3}$

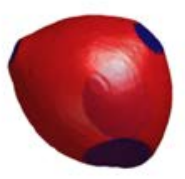

83,137 voxels $3.4^{*} 10^{-2} \mathrm{~mm}^{2}$

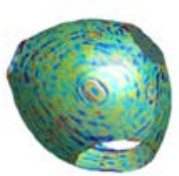

$0.023 \mu m^{-1}$
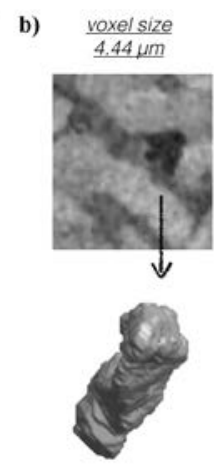

16.737 voxels

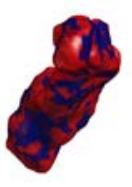

1227 voxels $2.4^{*} 10^{-2} \mathrm{~mm}^{2}$

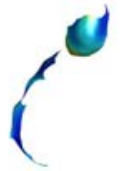

$0.031 \mu m^{-1}$ $1.46^{*} 10^{-3} \mathrm{~mm}^{3}$
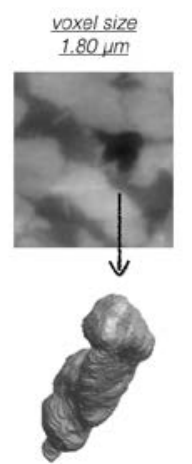

240,072 voxels $1.40^{*} 10^{-3} \mathrm{~mm}^{3}$

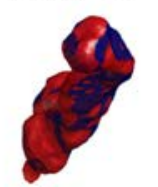

6568 voxels 2. $1^{*} 10^{-2} \mathrm{~mm}^{2}$

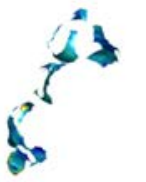

$0.048 \mu m^{1}$

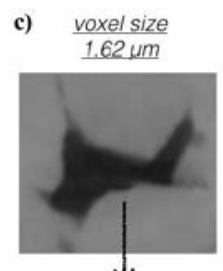

$\downarrow$
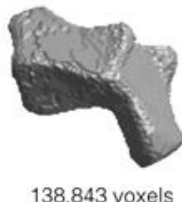
$5.90 * 104$

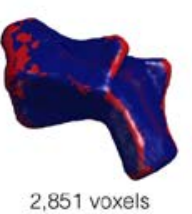

$7.5^{* 1} 10^{-3} \mathrm{~mm}^{2}$

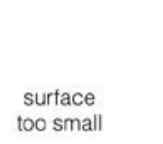

too small

Fig. 9.Effect of image resolution on curvature estimation analyzed for the same air ganglion isolated from a) the glass bead sample imaged with a voxels size of $1.62 \mu \mathrm{m}$ (GB-4X) and 0.64 $\mu \mathrm{m}(\mathrm{GB}-10 \mathrm{X})$, b) the Boise sample imaged with a voxel size of $4.44 \mu \mathrm{m}$ (BS-2X) and $1.8 \mu \mathrm{m}$ (BS-5X) and c) the Fontainebleau sample imaged with a voxel size of $1.62 \mu \mathrm{m}$ (FS-4X) and 0.64 $\mu \mathrm{m}$ (FS-10X). In each case, the Figure shows from top to bottom for both resolution: a 2D raw image, the 3D segmented air ganglion (with its volume in voxels and $\mathrm{mm}^{3}$ ), the visualization of the interface in red (with its surface in pixels and $\mathrm{mm}^{2}$ ), and the visualization of the mean curvature values presented by the interface. The details are provided in Table 3.a. 


\begin{tabular}{|c|c|c|c|c|c|c|c|c|}
\hline & $\begin{array}{c}\mu C T \\
\text { images }\end{array}$ & $\begin{array}{c}\text { Voxel size } \\
\quad(\mu \mathrm{m})\end{array}$ & $\begin{array}{l}\mathrm{N} \text { points } \\
\text { interface }\end{array}$ & $\begin{array}{c}\boldsymbol{K} \\
\left(\mu m^{-1}\right)\end{array}$ & $\begin{array}{c}S_{\boldsymbol{D}_{\boldsymbol{q}}} \\
\left(\mu \mathrm{m}^{-1}\right)\end{array}$ & $\begin{array}{c}S E_{\boldsymbol{q}} \\
\left(\mu \mathrm{m}^{-1}\right)\end{array}$ & $\begin{array}{c}\boldsymbol{P}_{\boldsymbol{c}} \\
(\mathrm{Pa})\end{array}$ & $\begin{array}{r}S E_{P c} \\
(\mathrm{~Pa})\end{array}$ \\
\hline \multirow[t]{6}{*}{ a) } & GB-4X & 1.62 & 13545 & 0.0219 & 0.0099 & 8.51E-05 & 3,148 & 12 \\
\hline & GB-10X & 0.64 & 83137 & 0.0226 & 0.0126 & 4.36E-05 & 3,260 & 6 \\
\hline & BS-2X & 4.44 & 1227 & 0.0309 & 0.0298 & 8.52E-04 & 4,450 & 123 \\
\hline & BS-5X & 2.8 & 6568 & 0.0483 & 0.0577 & 7.12E-04 & 6,955 & 103 \\
\hline & FS-4X & 1.62 & 0 & - & - & - & - & - \\
\hline & FS-10X & 0.64 & 6328 & 0.1243 & 0.1276 & $1.60 \mathrm{E}-03$ & 17,903 & 231 \\
\hline \multirow[t]{13}{*}{ b) } & \multirow{8}{*}{$\begin{array}{c}\text { GB-10X } \\
\text { isolated } \\
\text { ganglia }\end{array}$} & \multirow{8}{*}{0.64} & 83137 & 0.0226 & 0.0126 & 4.36E-05 & 3,260 & 6 \\
\hline & & & 2025 & 0.0222 & 0.0207 & 4.59E-04 & 3,191 & 66 \\
\hline & & & 1631 & 0.0220 & 0.0219 & 5.42E-04 & 3,174 & 78 \\
\hline & & & 2041 & 0.0213 & 0.0222 & $4.92 \mathrm{E}-04$ & 3,060 & 71 \\
\hline & & & 1604 & 0.0232 & 0.0240 & $6.00 \mathrm{E}-04$ & 3,347 & 86 \\
\hline & & & 3975 & 0.0200 & 0.0214 & $3.40 \mathrm{E}-04$ & 2,875 & 49 \\
\hline & & & 3343 & 0.0201 & 0.0226 & $3.90 \mathrm{E}-04$ & 2,887 & 56 \\
\hline & & & 1347 & 0.0157 & 0.0203 & 5.54E-04 & 2,254 & 80 \\
\hline & \multirow{5}{*}{$\begin{array}{c}\text { BS-5X } \\
\text { isolated } \\
\text { ganglia }\end{array}$} & \multirow{5}{*}{1.80} & 4628 & 0.0371 & 0.0216 & 3.17E-04 & 5,347 & 46 \\
\hline & & & 293 & 0.0431 & 0.0207 & $1.21 \mathrm{E}-03$ & 6,210 & 174 \\
\hline & & & 262 & 0.0271 & 0.0189 & 1.17E-03 & 3,908 & 168 \\
\hline & & & 466 & 0.0388 & 0.0219 & $1.01 \mathrm{E}-03$ & 5,594 & 146 \\
\hline & & & 988 & 0.0301 & 0.0271 & 8.61E-04 & 4,336 & 124 \\
\hline
\end{tabular}

Table 3.a) Effect of image resolution: interfacial curvature analysis conducted on the same air ganglion isolated from images acquired with different voxel sizes for the glass bead (GB-4X, GB10X), Boise (BS-2X, BS-5X) and Fontainebleau (FS-4X, FS-10X) samples, displayed in Fig. 9. b) Location on the mesh: interfacial curvature analysis conducted on selected portions of the entire interface of air ganglia isolated from the glass bead (GB-10X) and Boise (BS-5X) samples, displayed in Fig. 10. The calculation performed on the entire interface is highlighted in bold. For both a) and b) the Table lists the voxel size, the number of points on the interface used for the calculation, mean curvature $\kappa$ for the ganglion, standard deviation $S D_{g}$ and standard error $S E_{g}$ of curvature values calculated for each point of the interface, mean ganglion capillary pressure $P_{c}$, and standard error of capillary pressure values for the ganglion.

Thelocal variation of the curvature estimation on the interface was also investigated in order to assess the impact of interface identification on the curvature calculation, as the air/brine interface presented by a single air ganglion may change depending on the image acquisition, resolution and image processing. This analysis was conducted on the welldefined air ganglia isolated from the glass beads sample imaged with a voxel size of 0.64 $\mu \mathrm{m}(\mathrm{GB}-10 \mathrm{X})$ and from the Boise sample imaged with a voxel size of $1.8 \mu \mathrm{m}$ (BS-5X) that have been used for the sensitivity analysis presented in sub-section 2.4.3. For each isolated air ganglion, regions were selected randomly on the interface and the curvature was computed for the selected portions of the total interface, as displayed in Fig. 10, and detailed in Table 3.b. The calculation using the entire interface is the first raw, marked in bold. The results show that the seven selected portions of interface of the isolated ganglia extracted from GB-10X dataset present similar interfacial curvature distributions (Fig. 10.a) and curvature values $\kappa$, ranging from $0.016 \mu \mathrm{m}^{-1}$ to $0.023 \mu \mathrm{m}^{-1}$, with an average of 
$0.021 \mu \mathrm{m}^{-1}$ and a standard deviation from one $\kappa$ calculation to another of $0.002 \mu \mathrm{m}^{-1}$. On

2 average, the values calculated on the selected interfaces differ from the one calculated 3 using the entire identified interface by a bit less than $10 \%$. There is more discrepancy in curvature distributions between the different interfaces selected from the BS-5X ganglion (Fig. 10.b). The curvature values for the different portions of the interface range from $0.027 \mu \mathrm{m}^{-1}$ to $0.043 \mu \mathrm{m}^{-1}$, with an average of $0.034 \mu^{-1}$ and a standard deviation of 0.007 $\mu \mathrm{m}^{-1}$ and differ from the one calculated using the entire interface by $17 \%$. In general one can also note that the standard error of the mean curvature and capillary pressure is lower when the entire identified interface is used for calculation since it involves a higher number of points where the mean curvature is computed when averaging for the ganglion.
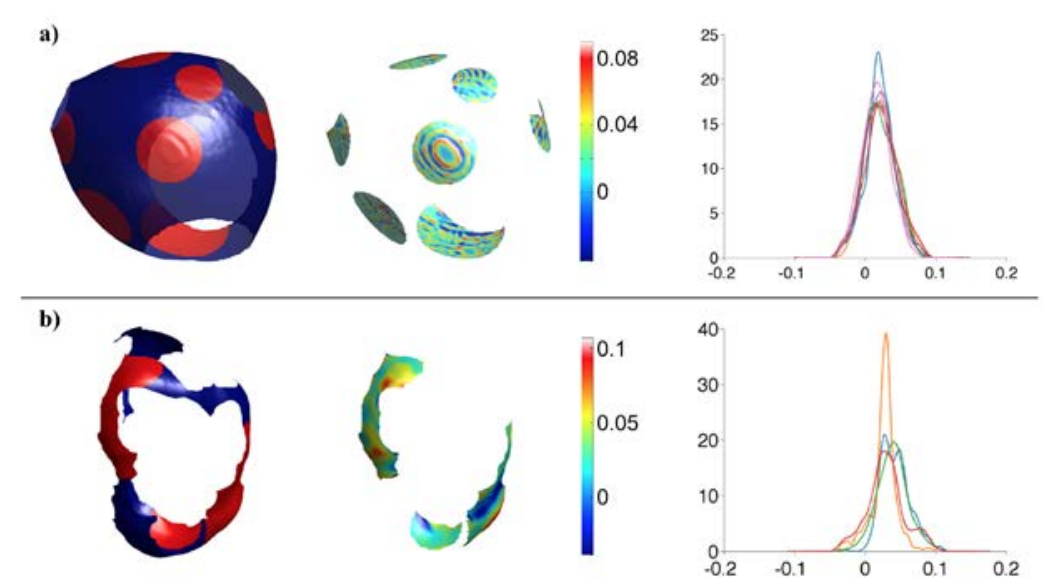

13

14

15

16

17

18

19

20

21

22

23

24

25

26

27

28

29

30

31

32

33

34

35

Fig. 10. Local variation of the curvature estimation on the interface analyzed for a single air ganglia isolated from a) the glass beads sample imaged with a voxel size of $0.64 \mu \mathrm{m}$ (GB-10X) and $\mathbf{b}$ ) the Boise sample imaged with a voxel size of $1.8 \mu \mathrm{m}$ (BS-5X). In each case, the Figure shows from left to right: a visualization of the selected portions of the interface (red), a visualization of the mean curvature values presented by the selected interfaces, and a plot of the corresponding curvature histograms. The details are provided in Table 3.b.

\subsubsection{Curvature analysis for the different rock types}

This sub-section presents the results of interfacial curvature calculations and capillary pressuresthe different sub-volumesanalyzed for each rock type.The results of the curvature analysis are displayed in Fig. 11, Fig. 12 and Fig.13for the sub-volumes of the Glass beads, Boise and Fontainebleau sample respectively. Each figure displays the results similarly: the results for a sub-volume are organized in column, where the first image is a visualization of the disconnected air ganglia, the second is a visualization of the air/brine interfaces, the third image is a visualization of the all themean curvature values displayed by the interfaces taken into account for the mean calculation, and the last image is a graph of the pdfs for the curvature values for each air ganglion.The average curvature of each ganglion is then plotted as a function of its total volume in Fig. 14. The results are also presented in terms of capillary pressure distributions for both sandstone samples in Fig. 15. These results are also summarized in Table 4where the average standard deviation and standard error of the mean for the curvature values 
1 presented by the interface of a single ganglion, $\left\langle S D_{g}\right\rangle$ and $\left\langle S E_{g}\right\rangle$ respectively, are first 2 listed, followed by the average mean curvature value presented by all the ganglia, $\langle k\rangle$, 3 and the standard deviation of the ganglia average curvature values $S D_{K}$, as well as the 4 corresponding average capillary pressure values and standard deviations, $\left\langle P_{c}\right\rangle$ and $S D_{P c}$ 5 (cf last paragraph of sub-section 2.4.3).

6

\begin{tabular}{|c|c|c|c|c|c|c|c|c|}
\hline $\begin{array}{c}\mu \mathrm{CT} \\
\text { images }\end{array}$ & $\begin{array}{c}\text { Voxel size } \\
\quad(\mu \mathrm{m})\end{array}$ & $\begin{array}{c}N \\
\text { ganglia }\end{array}$ & $\begin{array}{l}<S \boldsymbol{D}_{g}> \\
\left(\mu \mathrm{m}^{-1}\right)\end{array}$ & $\begin{array}{l}<\boldsymbol{S} \boldsymbol{E}_{g}> \\
\left(\mu \mathrm{m}^{-1}\right)\end{array}$ & $\begin{array}{c}<\boldsymbol{K}> \\
\left(\mu m^{-1}\right)\end{array}$ & $\begin{array}{c}S D_{K} \\
\left(\mu m^{-1}\right)\end{array}$ & $\begin{array}{l}<\boldsymbol{P}_{c}> \\
(\mathrm{Pa})\end{array}$ & $\begin{array}{l}S D_{P_{C}} \\
(\mathrm{~Pa})\end{array}$ \\
\hline GB-2X* & 3.28 & 5 & 0.009 & $1.2 \mathrm{E}-04$ & 0.008 & 0.002 & 1,107 & 308 \\
\hline GB-4X* & 1.62 & 3 & 0.011 & 2.3E-04 & 0.015 & 0.008 & 2,139 & 1,173 \\
\hline BS-2X+ & 4.44 & 73 & 0.234 & $8.1 \mathrm{E}-03$ & 0.042 & 0.042 & 6,071 & 6,106 \\
\hline BS- $5 \mathrm{X}^{+}$ & 1.80 & 90 & 0.068 & $1.8 \mathrm{E}-03$ & 0.040 & 0.020 & 5,782 & 2,957 \\
\hline BS-5X* & 1.80 & 102 & 0.066 & $1.8 \mathrm{E}-03$ & 0.054 & 0.033 & 7,803 & 4,742 \\
\hline BS- $5 \mathrm{X}^{\circ}$ & 1.80 & 38 & 0.061 & $1.7 \mathrm{E}-03$ & 0.032 & 0.020 & 4,617 & 2,889 \\
\hline FS-4X* & 1.62 & 107 & 0.205 & $1.0 \mathrm{E}-02$ & 0.110 & 0.113 & 15,893 & 16,340 \\
\hline FS-10X* & 0.64 & 20 & 0.099 & $3.1 \mathrm{E}-03$ & 0.147 & 0.093 & 21,110 & 13,401 \\
\hline
\end{tabular}

Table 4.Curvature analysis results for all the sub-volumes analyzed (more details regarding the sub-volumes can be found in Table 1. They all sample different volumes of the Glass-beads, Boise or Fontainebleau images, except BS- $2 \mathrm{X}^{+}$and $\mathrm{BS}-5 \mathrm{X}^{+}$which correspond to the exact same volume of Boise sample imaged with two different voxel sizes). For each image the table lists its name, voxel size, number of ganglia $N$ ganglia,average standard deviation $\left\langle S D_{g}\right\rangle$ and standard error $\left\langle S E_{g}\right\rangle_{\text {of }}$ curvature values for a ganglion, the average curvature presented by the ganglia $\langle k\rangle$, the standard deviation of the ganglia curvature values $S D_{K}$, the average capillary pressure presented by the ganglia $\left\langle P_{c}\right\rangle$ and the standard deviation of the capillary pressure values $S D_{P_{c}}$.

\section{Glass beads subsamples (GB-2X*, GB-4X*)}

Fig. 11.c and ghighlight the similarity of curvature values presented by the interfaces considered for the calculation. For both sub-volumes, the distributions of curvature values for each isolated air ganglia (Fig. 11.dand h)show that the interfaces of all identified ganglia present similar local values of mean curvature that are close to the average mean value for the ganglia. For a single air cluster, the average standard errors of the mean for the two sub-volumes are low and corresponds to 95\% confidence interval of \pm 33 and $\pm 65 \mathrm{~Pa}$, in terms of capillary pressure, for GB-2X* and GB-4X* respectively. The distributions graphs also show that the curvature values for each isolated air ganglia are similar one to another, as also clearly represented in Fig. 14.a. The average curvature $\langle k\rangle$ is $0.008 \mu^{-1}$ and $0.015 \mu \mathrm{m}^{-1}$ for GB-2X* and GB-4X* respectively, corresponding to mean capillary pressures $P_{c}$ of $1,107 \mathrm{~Pa}$ and 2,139 $\mathrm{Pa}$ for GB-2X* and GB-4X* respectively.It should be reminded that the two sub-volumes do not sample the same volume within the Glass-Beads sample. 

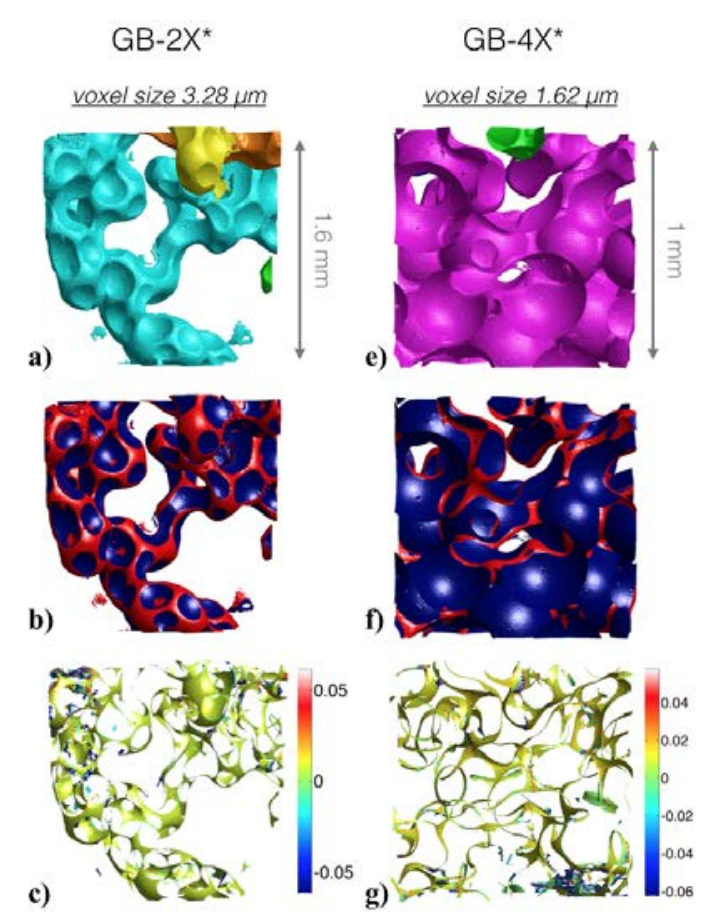

Fig. 11.Interfacial curvature analysis for the analyzed sub-volumes of the glass beads sample imaged with a voxel size of $3.28 \mu \mathrm{m}\left(\mathrm{GB}-2 \mathrm{X}^{*}\right.$ - graphs a) to d)) and of $1.62 \mu \mathrm{m}\left(\mathrm{GB}-4 \mathrm{X}^{*}\right.$ graphs e) to h)). a)ande)the disconnected air ganglia are represented with different colors. b)andf)the total air phase is represented in navy blue and the interfaces with the brine phase are colored in red. c) andg) the mean curvature is plotted for each portion of interface used for the calculation. d)andh)the mean curvature distribution is plotted for each separated air ganglion that presents interfaces large enough for the calculation.

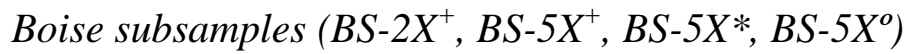

Fig. 12.c, g, $\mathbf{k}$ and odisplay visualizations of the curvature values presented by the interfaces considered for the calculation for $\mathrm{BS}-2 \mathrm{X}^{+}$, BS- $5 \mathrm{X}^{+}$, BS- $5 \mathrm{X}^{*}$ and $\mathrm{BS}-5 \mathrm{X}^{\circ}$ respectively. The corresponding curvature distribution histograms per air ganglia are shown in Fig.12.d, $\mathbf{h}, \mathbf{l}$ and $\mathbf{p}$. The results are detailed for the three sub-volumes of the sample imaged with a voxel size of $1.8 \mu \mathrm{m}$, and then for the sub-volume of the sample imaged with a voxel size of $4.44 \mu \mathrm{m}\left(\mathrm{BS}-2 \mathrm{X}^{+}\right)$, which represents the exact same volume as $\mathrm{BS}-5 \mathrm{X}^{+}$.

For the three sub-volumes imaged with a voxel size of $1.8 \mu \mathrm{m}$, Fig. 12.h, $\mathbf{I}$ and $\mathbf{p}$ show that the interfaces of all disconnected air ganglia present more broadly distributed local 
1 beads sub-volumes presented above.On average, the standard error of the mean for a 2 single ganglia $\left\langle S E_{g}\right\rangle$ is similar for all three sub-samples and is low, corresponding to $95 \%$ 3 confidence intervals in terms of capillary pressure around $\pm 490 \mathrm{~Pa}$. When compared with 4 BS-5X+, the air ganglia for BS-2X+ presentsa higher standard error for a single ganglion,

There is a significant discrepancy in the average ganglia curvature values $\kappa$ in between the three different sub-volumes images with the same resolution (Table 4)leading to mean capillary pressure estimates of 5,782; 7,803 and 4,617 for BS-5X ${ }^{+}$, BS-5X* and BS-5X respectively. However, one can note that the average mean curvature for the sub-volume images with the lower resolution (BS- $2 \mathrm{X}^{+}$) is very close to the value calculated for BS$5 \mathrm{X}^{+}$. The standard deviation of the mean curvature presented by the different air ganglia is $0.020 \mathrm{~mm}^{-1}$ for both BS- $5 \mathrm{X}^{+}$and BS-5X $\mathrm{X}^{\mathrm{o}}$ and is a bit higher for BS-5X* with a value of $0.033 \mu^{-1}$ (Table 2,Fig. 14.b). In addition, the figure highlights that the air ganglia presenting a mean curvature value that differs the most from the average are usually within the smallest ganglia, in terms of volume. It also shows that sub-volume BS- $2 \mathrm{X}^{+}$ presents a higher fraction of air ganglia with interfacial curvature values that are scattered further from the average value for the entire sub-volume. The standard deviation for that sub-volume is $0.042 \mu^{-1}$. However, in that case, it is not particularly correlated with the air ganglia volume.

\section{Fontainebleau subsamples (FS-4X*, FS-10X*)}

AlthoughFig. 13.c and g show that both sub-samples FS-4X* and FS-10X* present rather similar interfacial curvature, the distributions of curvature values for each isolated air ganglia differs (Fig. 13.d and h): whereas for FS-4X* most ganglia present similar distributions, the distributions presented by the air ganglia for FS-10X* vary from a ganglion to another and the deviation is also larger. These results include however all the interfaces that remain after deleting from the mesh the vertices that belong to the rock/air interface as explained in sub-section 2.4.3, which is the procedure that was successfully applied to the glass beads and Boise images. As mentioned in the Material and Methods section, a high fraction of flat air/brine interfaces are still present in the case of the Fontainebleau sandstone, due to the presence of thin films between the air phase and the rock. These interfaces, which are likely to be supported by the solid, significantly lower the mean interfacial curvature values of air ganglia and were therefore removed for the curvature calculation listed in Table 4and displayed in Fig. 14and Fig. 15.

The average standard error of the mean, for a single ganglion, is on average one order of magnitude higher for FS-4X* than for FS-10X*, and also generally higher than for Boise sandstone. It corresponds to 95\% confidence intervals in terms of capillary pressure of $\pm 3096 \mathrm{~Pa}$ for the lower resolution and $\pm 874 \mathrm{~Pa}$ for the higher resolution. The average ganglia curvature values $\kappa$ are also different for the two sub-volumes, leading to mean capillary pressure estimates of 15,893 Pa for FS-4X* and 21,110 Pa for FS-10X*. The standard deviation of the mean curvature presented by the different air ganglia is also higher for the lower resolution sub-sample (Fig 14.c, Fig.15). As already noticed for 
1 Boise sub-samples, Fig. 14.c also highlightsthat higher curvature values are more 2 frequent for air ganglia of smaller volume.

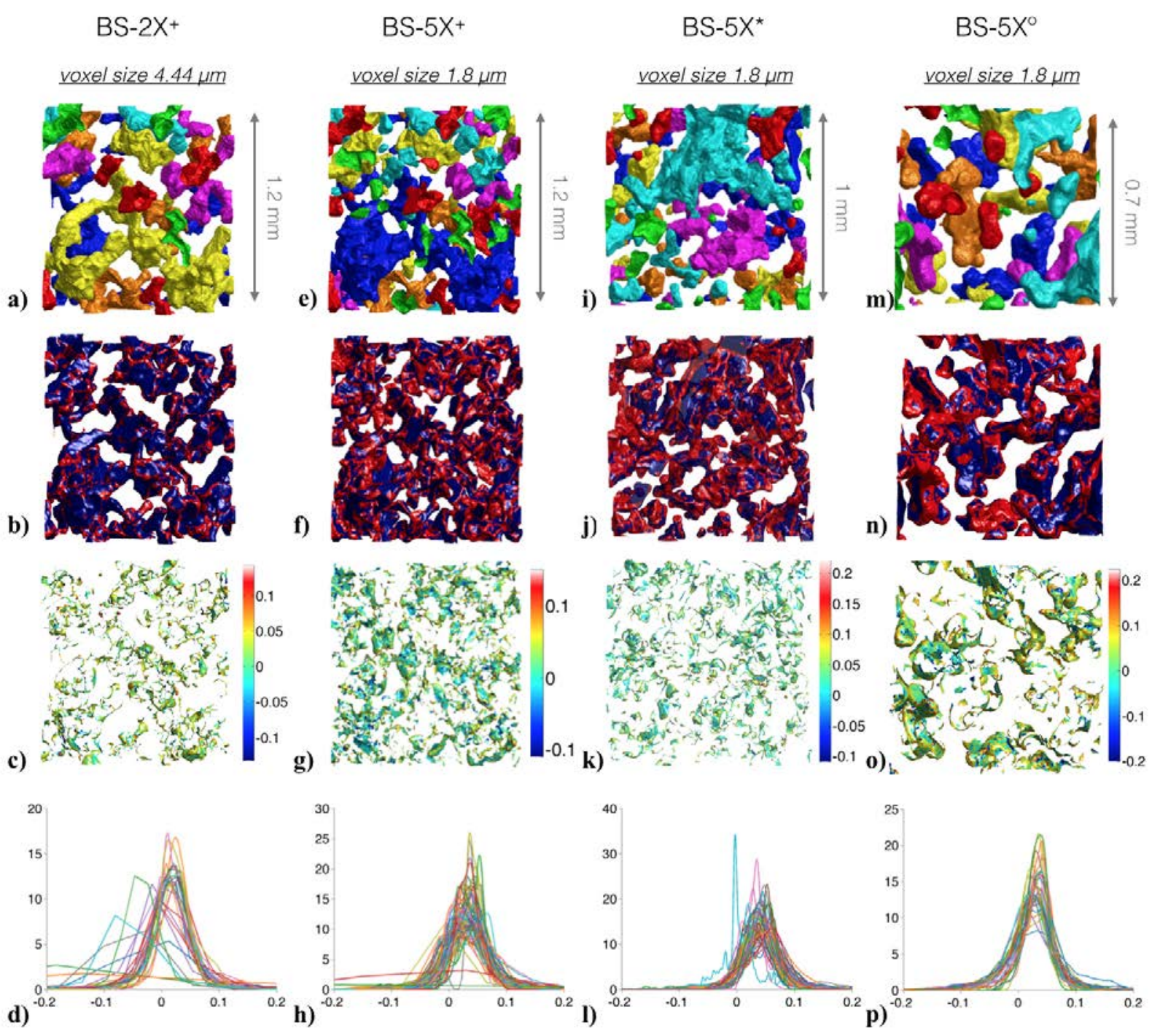

Fig. 12.Interfacial curvature analysis for the analyzed sub-volumes of the Boise sandstone sample imaged with a voxel size of $4.44 \mu \mathrm{m}\left(\mathrm{BS}-2 \mathrm{X}^{+}\right.$- figuresa) to d)) and of $1.8 \mu \mathrm{m}\left(\mathrm{BS}-5 \mathrm{X}^{+}\right.$-

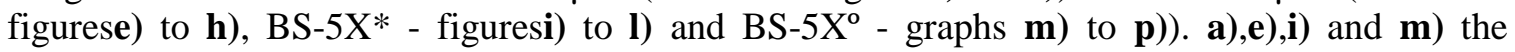
disconnected air ganglia are represented with different colors. b), f), j) and $\mathbf{n}$ ) the total air phase is represented in navy blue and the interfaces with the brine phase are colored in red. c), g), k)and $\mathbf{o}$ ) the mean curvature is plotted for each portion of interface used for the calculation. d), h), l) and p) the mean curvature distribution is plotted for each separated air ganglion that presents interfaces large enough for the calculation. 


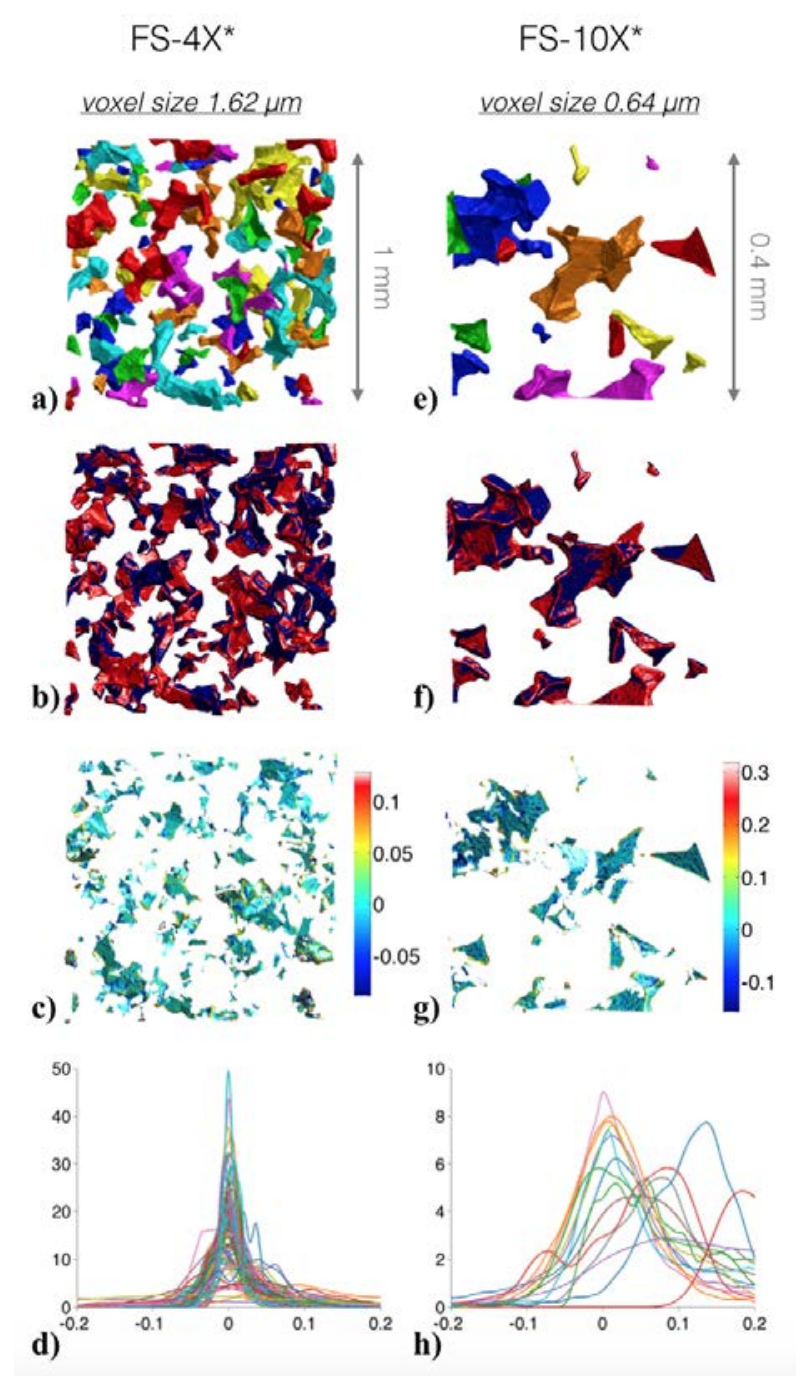

Fig. 13.Interfacial curvature analysis for the analyzed sub-volumes of the glass beads sample imaged with a voxel size of $1.62 \mu \mathrm{m}$ (FS-4X* - graphs a) to d)) and of $0.64 \mu \mathrm{m}$ (FS-10X* graphs e) to h)). a)ande) the disconnected air ganglia are represented with different colors. b)andf) the total air phase is represented in navy blue and the interfaces with the brine phase are colored in red. c) andg) the mean curvature is plotted for each portion of interface used for the calculation. d)andh) the mean curvature distribution is plotted for each separated air ganglion that presents interfaces large enough for the calculation. 

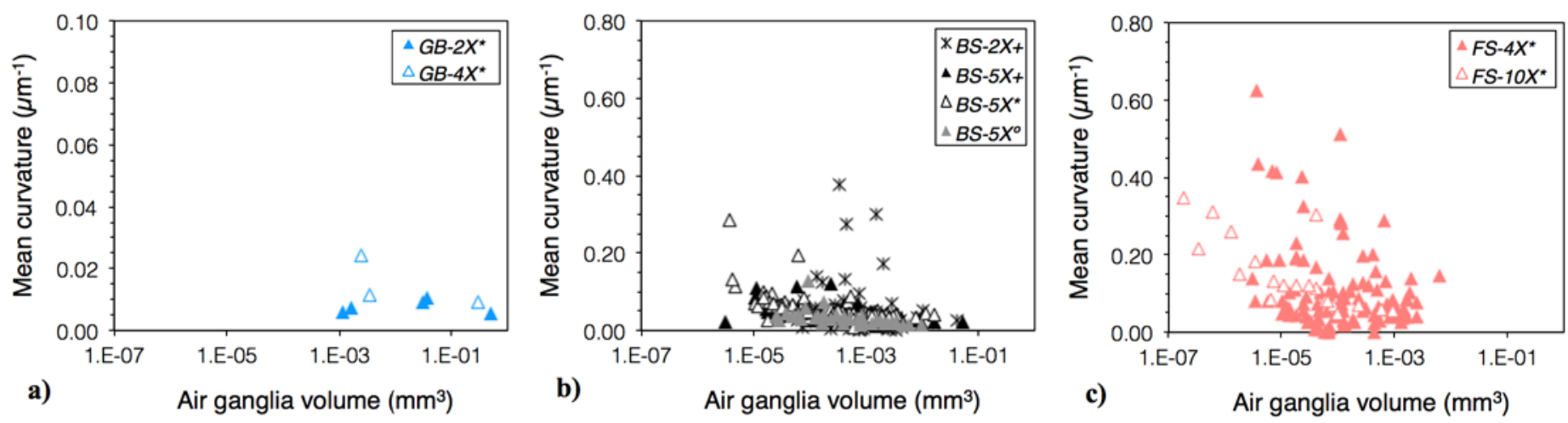

1 Fig. 14.Air ganglia mean curvature $\left[\mathrm{\mu m}^{-1}\right]$ as a function of the air ganglia volume $\left[\mathrm{mm}^{3}\right]$ for the 2 analyzed sub-volumes of $\mathbf{a})$ the glass beads sample, $\mathbf{b}$ ) the Boise sandstone sample and $\mathbf{c}$ ) the 3 Fontainebleau sandstone sample.

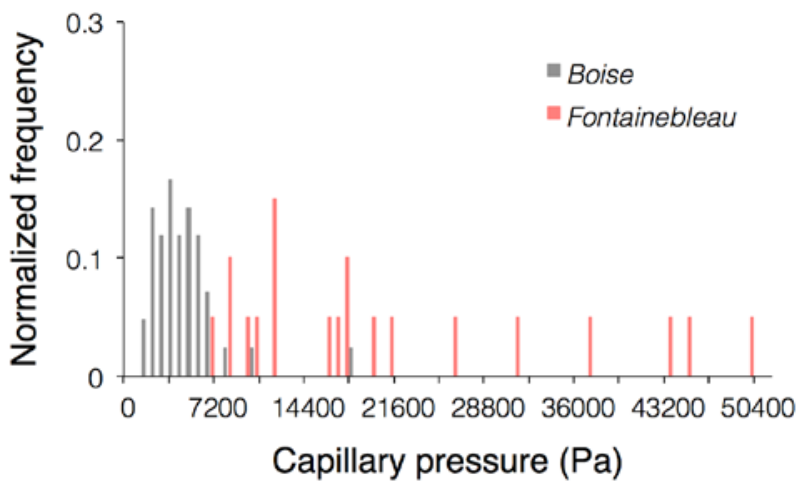

Fig. 15.Capillary pressure distribution for Boise sandstone sample (represented by sub-sample BS- $5 \mathrm{X}^{\circ}$ ) and Fontainebleau sandstone sample (represented by sub-sample FS-10X*)

\section{Discussion}

\subsection{Identifying gas ganglia and gas/brine interfaces}

Since the ability to accurately characterize the trapped non-wetting phase and identify the interface shared with the wetting phase is an important factor to estimate capillary pressure distribution in rocks using interfacial curvature calculations on X-ray microtomography images, this issue was addressed first. As expected, it is highly dependent on both i) the poresize and shapeof the scanned rock sample and ii) the image resolution of the scans.

\section{Glass beads}

Porous samples which have a pore structure consisting of well-connected flow paths of large diameter and low or moderate pore bodyto pore throat ratio, represented here by the glass beads sample, display large nonwetting and wetting phase features with very clearly identifiable interfaces between the two fluids. The glass beads sample presents a mean 
1 pore-throat diameter, estimated with MICP, about 30 times larger than the lower image

2 resolution (GB-2X, voxel size of $3.28 \mu \mathrm{m}$ ) and even the smaller features, presented by 3 the brine phase, are more than one order of magnitude larger than the highest voxel size. 4 Although the same object would be described by more voxels using higher resolution 5 images, all the features are still represented by a very high number of voxelsat the lower magnification. In addition, the use of the lower resolution allows imagingof a larger volume. Even though the glass beads pore space is very homogeneous and could be well represented by a smaller volume, the trapped gas consists of a single well-connected cluster spanning through most of the sample. This is in good agreement with previous Xray microtomography analysis of trapped nonwetting phase in water-wet glass beads packs conducted by Armstrong et al. (2012a), Chaudhary et al. (2013) and Georgiadis et al. (2013). For such rock types displaying a well-connected large pore structure, the volume of the sample becomes more critical for fluid flow investigations than the voxel size.

Although this is not directly in the scope of the paper, it is worth mentioning that, for this sample, the large difference in saturation between the $2 \mathrm{X}$ and $4 \mathrm{X}$ scans is due to movement of fluid phases in between the two image acquisitions. Motion artifacts were actually still present on the 10X scans. This suggests that for such pore morphologies, the residual trapping process seem to require longer equilibration time than usually assumed. Armstrong et al. (2012a) reported that 20 min was not enough. The present study suggests that even five hours is not sufficient to have complete equilibrium in this class of systems.Recent work from McClure et al. (2016a, 2016b) also indicates that relaxation times for curvatures may range from several hours to a day.

\section{Sandstones}

If one considers that at least three voxels are required as a minimum to correctly identify an object, then the images acquired with the $2 \mathrm{X}$ magnification (voxel sizes of $4.44 \mu \mathrm{m}$ for Boise and $3.28 \mu \mathrm{m}$ for Glass beads and Fontainebleau) could not unambiguously probe any features smaller than about $10-13 \mu \mathrm{m}$. Fig. 1 indicates that $20 \%$ and $30 \%$ of the pore network exists below this threshold for the Boise and Fontainebleau samples respectively. Therefore, whereas this resolution is sufficient to accurately probe the pore network displayed by the Glass beads sample, higher resolution is needed for a more precise characterization of the microstructure for these standard sandstone samples. The comparison of porosity and saturation values computed on different sub-volumes confirms that Boise sandstone is more heterogeneous than Fontainebleau sandstone. Boise microstructure is unique and quite different than the average sandstone due to quartz overgrowth bridges as well as the abundance of platy mica grains (Prasad, 2011). Laminations present in the sample lead tomore variability and an overall significant heterogeneity of the pore structure. The data also show that Fontainebleau sandstone exhibits a higher residual gas saturation. In Fontainebleau sandstones, the reduction of porosity by quartz overgrowths around the grains leads to angular pores between quartz grains of moderate size and very thin planar pores between two grains (Bourbie and Zinszner, 1985). This pore space morphology, characterized by a large aspect ratio between the pore bodies and throats is known to favor trapping by snap-off (Tanino and 
1 Blunt, 2011). Hamon et al. (2001) measured residual gas saturation in different types of sandstones, including a similar Fontainebleau sample, and reported that Fontainebleau trapped much more gas ( $70 \%$ saturation) than the other shaly samples, comparable to Boise sandstone (40 to 50\% maximum saturation). Sok et al. (2002) performed imbibition site-based invasion percolation simulations on Fontainebleau sandstone networks and also concluded in higher gas saturation for low porosity Fontainebleau.

The sub-volumes of $1 \mathrm{~mm}^{3}$ investigated for the two sandstones with voxel sizes around $1.7 \mu \mathrm{m}$ sample a large amount of disconnected ganglia (114 for Boise and 157 for Fontainebleau) and the largest ganglia contribute to less than $20 \%$ of the total gas phase (17.2\% for Boise and $12.9 \%$ for Fontainebleau); we can then assume that these volumes are well representative of the gas ganglia distribution. Because of the heterogeneity of Boise sandstone different sub-volumes might present different porosity and fluid saturation values; however, the characteristics of the air phase is very consistent. The cluster size analysis of air ganglia for all different sub-volumes investigated for Boise sandstone show indeed very similar results, with air ganglia volumes distributed over four orders of magnitude. The distribution of air ganglia volume displays a similar trend for Fontainebleau sandstone but with generally smaller air ganglia. Iglauer et al. (2011) showed that Doddington sandstone was trapping clusters from a hundred voxels to ten thousands voxels. Andrew et al. (2014a) also reported that significant proportions of $\mathrm{scCO}_{2}$ is trapped in various sandstone and carbonate samples in clusters with sizes ranging over five orders of magnitude, with better connected pore spaces having more large clusters relative to small clusters. This is supported by the comparison of the results for the Fontainebleau sandstone presented in this study and results reported by Kumar et al. (2010) for a more porous Fontainebleau sample, exhibiting larger pore sizes and better connectivity; in this case, the authors imaged larger size clusters that may span more than hundreds of pores. For both sandstones investigated in the present paper, the mean air ganglia volume estimated from the cluster size study suggests thatdespite the presence of few large air ganglia spanninga larger number of pore bodies and throats, most disconnected air ganglia are located in one or few pores.The most significant difference between the two sandstones lies in the size and shape of the interfaces that gas ganglia share with the brine phase. For Boise sandstone the equivalent diameter for the brine phase is larger than the throat diameter estimated with MICP and both are larger than the voxels size. However, in the case of Fontainebleau sandstone the equivalent diameter for the brine phase is smaller than the MICP throat diameter and is close to the size of few voxels. This is both due to the very high gas saturation, hence low fraction of brine in the sample, and the fact that the wetting phase occupies the smallest part of the pore space, which in the case of Fontainebleau sandstone can be very close to the voxels size. In order to have a better identification of the interfaces for curvature calculations the highest resolution (voxel size of $0.64 \mu \mathrm{m}$ ) is necessary for rocks presenting similar pore and throat sizes than those displayed by Fontainebleau sandstone, whereas the medium resolution (voxels size of $1.8 \mu \mathrm{m}$ ) allows a good representation of the interfaces for Boise sandstone or any type of rocks presenting a similar pore space topology and morphology.

\subsection{Measuring pore-scale capillary pressure}

46 
As expected, the mean curvature is low for trapped ganglia in the glass beads sample and significantly larger for trapped ganglia in the Fontainebleau Sandstone in comparison to the Boise sandstone due to the pore morphology(Fig. 14).Armstrong et al. (2012a) reported curvatures of one order of magnitude lower $\left(0.001\right.$ to $\left.0.002 \mathrm{~mm}^{-1}\right)$ in a glass beads packs with much larger pores than our glass beads sample.In their study of a 8 Ketton limestone, Andrew et al. (2014b) measured a mean curvature of $0.01 \mu^{-1}$, four times smaller than for the Boise sandstone sample presented here, which is also consistent since Boise presents smaller and more angular pores than the Ketton sample. To a first order, the mean curvatures values for the three samples we investigated lead to mean capillary pressures that are in good agreement with the MICP measurements for the three samples (Fig. 16). One can note that the mean capillary pressure estimated from the interfacial curvature between the trapped gas ganglia and the brine is in the order of magnitude of the entry pressure for each rock. Andrew et al. (2014a) observed in a Ketton limestone that the curvature of the ganglia was controlled by the size of the neighboring throats. In the post-imbibition context of geological storage, it is therefore plausible that the capillary pressures of disconnected ganglia will be, to a first order, well approximated by the capillary entry pressure of the rock. This does not mean that the system is at equilibrium, however.

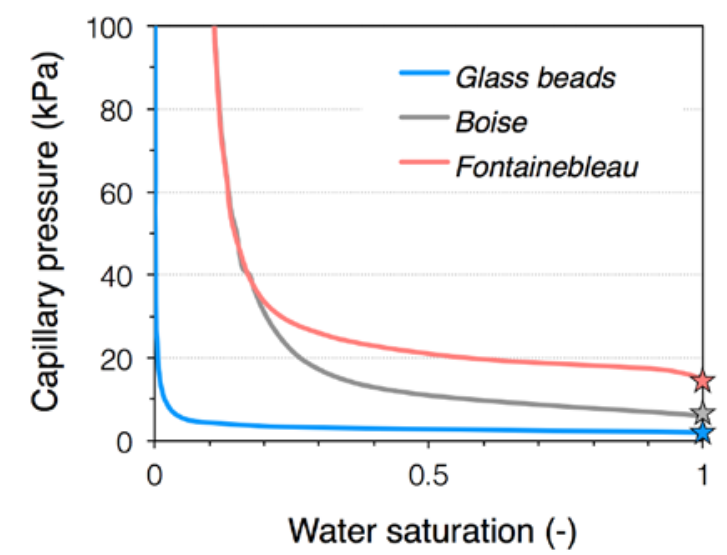

23 Fig. 16.Capillary pressure curves for air/water on the sintered glass beads sample (blue line), Boise sandstone (grey line) and Fontainebleau sandstone (pink line), converted from Hg/air MICP measurements. The entry pressures, represented by stars on the graphs, are about 2,000 $\mathrm{Pa}$ for the glass beads sample, 6,000 Pa for Boise sandstone and 15,000 Pa for Fontainebleau sandstone.

\section{Variability of capillary pressure measured on a single ganglion}

The analysis of the impact of image resolution and interface identification shows that very similar curvatures are estimated for a well-rounded gas bubble with a range of resolutions or using different portions of the interface (Fig. 9a, Fig. 10a). The error will however be decreased when using higher resolution images and the entire interface that 35 can be identified, leading to higher confidence in capillary pressure estimates (Table 3). 36 For gas ganglia presenting more complex shapes, a different resolution can lead to a 
different interface identified (Fig $\mathbf{9 b}$ and $\mathbf{c}$ ) and the capillary pressure of the same gas ganglia can vary from 4,450 Pa to 6,955 Pa for instance for a gas ganglia from the Boise sample (Table 3a). It can be seen on the 2D raw image displayed in the Figures that the quality of the high resolution image is significantly enhanced and the segmentation is therefore more likely to be reliable resulting in improved curvature estimates, not to mention the fact that a same object is described by more voxels with a higher resolution, thus reducing curvature calculation errors. For such gas ganglia, the comparison between curvature values calculated using the entire identified interface or just a portion of the interface lead to noticeable variation in the curvature, hence capillary pressure estimates exhibit similar variability (Fig. 10b, Table 3b). One possible explanation to the measured differences in capillary pressures is that there are measurement errors. Estimating the curvature of the surface is the product of a series of complicated image processing steps. Uncertainty is in particular associated with image segmentation step (e.g. Wildenschild and Sheppard, 2013). A second explanation is that the interfaces are supported by a solid surface, and we can therefore not apply Laplace's law to link mean curvature to capillary pressure directly. A third possibility is that isolated brine/air/grain surfaces are "pinned" and represent contact angle hysteresis.If the capillary pressure variability across individual ganglia is real, then either the pressure of the gas inside the ganglion is nonuniform, or the pressure in the liquid is non-uniform, or both are non-uniform. Nonuniform pressures do not appear likely however, especially since the brine phase is well connected.

In general, the standard error of the curvature values calculated for all points of the interface of a ganglion is low compared with the average curvature value for the ganglion and it can be concluded that the curvature calculations yields confident capillary pressure estimates, especially for the Glass Beads dataset and the Boise and Fontainebleau imaged with the highest resolution (BS-5X dataset, and FS-10X dataset).

\section{Variability of capillary pressure across a population of ganglia}

This sub-section summarizes the major findings regarding the ganglia capillary pressure distributionsfor the two sandstones.The comparison of the exact same sub-volume of Boise sample imaged with two different resolution $\left(\mathrm{BS}-2 \mathrm{X}^{+}\right.$and $\mathrm{BS}-5 \mathrm{X}^{+}$) shows that more trapped gas ganglia are identified on the higher resolution image due mostly to the identification of a higher amount of small-size ganglia (Fig. 8, Table S2). Although for the lower resolution image fewer interfaces are used for the curvature calculation and less voxels describe these interfaces, the mean curvature value for the entire sub-volume does not differ much from the one calculated on the sub-volume imaged with a higher resolution, leading to a similar mean capillary pressure value. However, the standard deviation of mean curvature value for the disconnected gas ganglia is two times bigger for the higher resolution image, which may yield different conclusions regarding the distribution of capillary pressures and the stability of residually-trapped gas. Considering that the confidence for curvature calculations is significantly increased for highresolution images, it would be recommended to use similar voxel sizes (below $2 \mu \mathrm{m}$ at least) for interfacial curvature analysis in sandstone rocks, as well as for any types of

46 similar investigation such as contact angle measurement, in rocks presenting comparable 
1 pore structure, in particular pore bodies and throats size and shape. The analysis of the

2 different Boise sub-volumes suggest however that there is a noticeable sampling effect 3 probably due to the heterogeneity of the sample pore structure, leading to differences in 4 mean capillary pressure as well as their distribution depending on the sub-volume investigated. Most air ganglia have similar size and present similar curvature value but the amount of smaller air ganglia, which present significantly higher curvatures,varies from on sub-volume to another (Fig. 14.b). Hence, the mean capillary pressure ranges from about 4,600 to 7,800 $\mathrm{Pa}$ for the same Boise sample.

For a similar number of gas ganglia investigated, Fontainebleau sandstone presents a larger number of ganglia having higher curvatures than the averagecompared with Boise sandstone (Fig. 15). Although the general mean curvature for Fontainebleau sample is higher than for Boise sample due to the pore space topology, the Fontainebleau sample does not have a higher proportion of small gas ganglia than Boise sample imaged with similar resolution (BS-5X and FS-4X). The more distributed values of curvatures for Fontainebleau is likely due to the geometry of the interfaces used for the curvature calculationswhich present a higher degree of variability than for Boise sandstone. Even though most planar interfaces were removed for the calculation, the portions of interfaces of interest may display significantly different curvature imposed by the pores and throats shape, as depicted in Fig. 9c. For this type of sandstone it is important to note that the number of voxels representing the interfaces used for the curvature calculation is smaller, leading to potentially higher error than for Boise sandstone, even when the calculation is done using the highest resolution sub-volume of Fontainebleau (FS-10X). In addition Fig. 9c also confirms the necessity of using a submicron voxel size for this type of sandstone in order to have more accurate results. One issue remains the very small size of sample investigated when using very high image resolution and the current technical impossibility to perform flow experiment in a pressure vessel, necessary to investigate $\mathrm{scCO}_{2} /$ brine systems with reservoir conditions, using a sample size that would allow submicron resolution image acquisition. Another issue that may be raised when using a higher resolution is the identification of thin films of brine. Along the surface of the gas phase that is in contact with the thin films supported by the rock grains, Laplace's law is not applicable. The portion of the interface that is in contact with these films should then be removed for the purpose of capillary pressure estimation, which complicates the analysis procedure.

\section{Implications for Ostwald ripening}

For both sandstone samples the disconnected gas ganglia may present capillary pressures showing differences that are statistically significant and Ostwald ripening would result in transferring gas from ganglia with higher capillary pressures to surrounding ganglia with lower capillary pressures.

In the case of Boise sandstone and for all the analyzed sub-volumes, the ganglia presenting higher capillary pressures consist of small gas ganglia that represent a minor fraction of the trapped gas phase. Since most other gas ganglia display almost identical capillary pressure, it can be assumed that Ostwald ripening would concern only a very 
1 small fraction of gas and would therefore not be an important mechanism for

2 remobilizing the trapped gas in that type of sandstone.

3
The larger distribution in capillary pressures presented by the Fontainebleau sandstone sub-volumes would result in more gas transfer by Ostwald ripening than for Boise sandstone. However the smaller average throat dimensions and longer pore channel length, characteristic of low porosity Fontainebleau sandstone (Lindquist et al., 2000), would significantly increase the diffusion time.

The results of this study are not intended to provide definitive conclusions one way or another regarding the potential for Ostwald Ripening to remobilize residually trapped $\mathrm{CO}_{2}$. Instead the goal is to develop and demonstrate experimental methods (with associated uncertainty quantification) to address the questions, do capillary pressure differences exist between gas clusters that could provide a driving force for Ostwald Ripening and can we measure them? The answer to these questions is yes: there are differences in capillary pressures between gas clusters and we can measure them. Fully addressing the question of whether or not these capillary pressure gradients can remobilize residually trapped $\mathrm{CO}_{2}$ requires multi-physics and multi-scale modeling on a larger spatial scale than is imaged here. With regard to acquiring the data sets needed to populate and validate these models, the trade-off between resolution and sample volume is evident. The larger the sample volume, the higher the probability that heterogeneities and gas cluster dimensions and topology will be fully sampled. Larger sample volumes however lead to lower spatial resolution, which results in poorer quality (and potentially erroneous) capillary pressure measurements. Advances in imaging technology that allow higher resolution on larger samples will be beneficial in this regard.

\section{Conclusion}

We presented a series of experiments providing multi-scale X-ray microtomography images of representative residually-trapped gas in three different sampletypes: a sintered glass-beads sample, a Boise sandstone sample and a Fontainebleau sandstone sample. The method to calculate interfacial curvatures was efficiently applied to the three samples leading to mean capillary pressure values in agreement with the literature and MICP measurements.

The analysis of the trapped gas in the two sandstones, which mostly consists of ganglia isolated to one or few pores, highlights the impact of image resolution and interface identification on the curvature estimates. Sub-micron resolution is recommended to lead such investigation in real rocks as it increases confidence in interfacial curvature calculations due to the high number of voxels representing the interfaces of interest. Higher resolution may however result in the identification of thin films of brine, which complicates curvature estimation.

A distribution of capillary pressures is seen for both sandstones, to a higher extent for Fontainebleau sandstone, suggesting that Ostwald ripening could occur and result in gas transfer from ganglia having higher capillary pressures to neighbor ganglia having lower 
1 capillary pressures. However, although some small gas ganglia may have higher capillary

2 pressures, a high proportion of the gas phase consists of ganglia having similar capillary 3 pressures, suggesting that Ostwald ripening could be limited for remobilizing residually4 trapped gas. Likewise, we cannot determine from this experiment whether a cyclical 5 process involving Ostwald ripening could yield transport of residually-trapped $\mathrm{CO}_{2}$ over

8 It should however be noted that this study investigates the capillary pressure distribution 9 for a single homogeneous rock, and difference in pore sizes between different portion of 10 a rock at a larger scale will result in differences in capillary pressure that could drive significant laminations and sorting differences.

\section{Acknowledgment}

This research was supported by the Center for Nanoscale Control of Geologic $\mathrm{CO}_{2}$, an Energy Frontier Research Center funded by the U.S. Department of Energy, under contract number DE-AC02-05CH11231. C. Garing and S.M. Benson also acknowledge support from The Global Climate and Energy Project (GCEP) at Stanford.Microtomographic imaging was performed with the assistance of Alastair MacDowell and Dula Parkinson at the Advanced Light Source, Beamline 8.3.2, supported by the U.S. DOE Office of Science, Office of Basic Energy Sciences(DE-AC02-05CH11231).

\section{References}

Andrew, M., Bijeljic, B., and Blunt, M., 2014a. Pore-scale imaging of trapped supercritical carbon dioxide in sandstones and carbonates, International Journal of Greenhouse Gas Control, vol. 22, p 1-14

Andrew, M., Bijeljic, B., and Blunt, M.J., 2014b.Pore-by-pore capillary pressure measurements using X-ray microtomography at reservoir conditions: Curvature, snap-off, and remobilization of residual CO2, Water Resources Research, vol. 50, n¹1, p. 8760-8774

Andrew, M., Menke, H., Blunt, M. J., and Bijeljic, B., 2015. The imaging of dynamic multiphase fluid flow using synchrotron-based X-ray microtomography at reservoir conditions, Transport in Porous Media, doi: 10.1007/s11242-015-0553-2

Armstrong, R.T., Porter, M. L., and Wildenschild, D., 2012a.Linking pore-scale interfacial curvature to column-scale capillary pressure, Advances in Water Resources, vol. 46, p. 55-62

Armstrong, R. T., Pentland, C. H., Berg, S., Hummel, J., Lichau, D., and Bernard, L., 2012b. Estimation of curvature from micro-CT liquid-liquid displacement studies with pore scale resolution, International Symposium of the Society of Core Analysts, Aberdeen, Scotland, UK, 27-30 August 2012, SCA2012-55

Armstrong, R. T., and Berg, S., 2013. Interfacial velocities and capillary pressure gradients during Haines jumps, Physical Review E, vol. 88, 043010, doi:10.1103/PhysRevE.88.043010

Armstrong, R. T., Georgiadis, A., Ott, H., Klemin, D., and Berg, S., 2014. Critical capillary number: Desaturation studied with fast X-ray computed microtomography, Geophysical Research Letters, vol. 41, p. 55-61, doi:10.1002/2013GL058075 
1 Armstrong, R. T., McClure, J. E., Berrill, M. A., Rücker, M., Schlüter S., and Berg, S., 2016. Beyond Darcy's law: The role of phase topology and ganglion dynamics for two-phase flow, Physical Review E., col. 94, 0433113, doi:10.1103?PhysRevE.94.043113

Bachu, S., 2008. $\mathrm{CO}_{2}$ storage in geological media: Role, means, status and barriers to deployment, Prog. Energy Combust. Sci., vol. 34, n², p 254-273

Bear, J., 1972. Dynamics of fluids in porous media, Elsevier, New-York

Benson, S. M., and Cole, D. R., 2008. $\mathrm{CO}_{2}$ sequestration in deep sedimentary formations, Elements, vol. 4, p 325-331

Blunt, M. J.,Bijeljic, B., Dong, Hu, OUssamaGharbi, Iglauer, S., Mostaghimi, P., Paluszny, A., and Pentland, C., 2013. Pore-scale imaging and modeling, Advances in Water Resources, vol. 51, p 197-216

Bourbie, T., and Zinszner, B., 1985.Hydraulic and acoustic properties as a function of porosity in Fontainebleau sandstone, J. Geophys. Res., vol. 90, nº 11,p. 524-532

Celia, M.A., and Nordbotten, J. M., 2009. Practical Modeling Approaches for Geological Storage of Carbon Dioxide, Ground Water, Vol. 47, p. 627-638

Chaudhary, K., Cardenas, M. B., Wolfe, W. W., Maisano, J. A., Ketcham, R. A., and Bennett, P. C., Pore-scale trapping of supercritical $\mathrm{CO}_{2}$ and the role of grain wettability and shape, Geophysical Research Letters, vol. 40, p. 3878-3882

Cnudde, V., and Boone, M. N., 2013. High-resolution X-ray computed tomography in geosciences: a review of the current technology and applications, Earth Science Reviews, doi:10.1016/j.earscirev.2013.04.003

Cohen-Steiner, David, and Jean-Marie Morvan, 2003. Restricted delaunay triangulations and normal cycle, Proceedings of the nineteenth annual symposium on Computational geometry, ACM

DePaolo D. J., and Cole, D. R., 2013. Geochemistry of Geologic Carbon Sequestration: An Overview, Reviews in Mineralogy and Geochemistry, vol. 77, p. 1-14

Desbrun, M., Meyer, M., Schroeder, P., and Barr, A.H., 1999.Implicit fairing of irregular meshes using diffusion and curvature flow, Proceedings of the 26th annual conference on Computer graphics and interactive techniques, ACM, p. 317-324

Dierick, M., Masschaele, B., and Van Hoorebecke, L., 2004.Octopus, a fast and user-friendly tomographic reconstruction package developed in LabView ${ }^{\circledR}$, Measurement Science and Technology, vol. 15, p.1366-1370.

Dominguez, A., Bories, S., and Prat, M., 2000. Gas cluster growth by solute diffusion in porous media. Experiments and automaton simulation on pore network, Int. J. Multiph. Flow, vol. 26, p. 1951-1979

Epstein, P. S., and Plesset, M. S., 1950. On the Stability of Gas Bubbles in Liquid-Gas Solutions, J. Chem. Phys., vol. 18, no 11, pp. 1505-1509

Federer, H., 1959. Curvature measures, Transactions of the American Mathematical Society, vol. 93, nº3, p. 418-491.

40 Geogiardis, A., Berg, S., Makurat, A., Maitland, G., and Ott, H., Pore-scale micro-computedtomography imaging: Nonwetting-phase cluster-size distribution during drainage and imbibition, Physical Review E, vol. 88, doi:10.1103/PhysRevE.88.033002 
1 Goldobin, D. S., and Brilliantov, N. V., 2011. Diffusive counter dispersion of mass in bubbly

2 media, Phys. Rev. E, vol. 84, n 5, p. 056328

3 Goodman, A., Hakala, A., Bromhal, G., Deel, D., Rodosta, T., Frailey, S., Small, M., Allen, D.,

4 Romanov, V., Fazio, J., Huerta, N., McIntyre, D., Kutchko, B., and Guthrie, G., 2011, US DOE

methodology for the development of geologic storage potential for carbon dioxide at the national and regional scale, International Journal of Greenhouse Gas Control, Vol. 5., p. 952-965

Greenwood A., 1956.The growth of dispersed precipitates in solutions, ActaMellaturgica, vol. 4, 8 p. $243-248$

Hamon, G., Suzanne, K., Billiotte, J, and Trocme, V., 2001. Field-Wide Variations of Trapped

Herring, A. L., Andersson, L., and Wildenschild, D., 2016. Enhancing residual trapping of supercritical $\mathrm{CO}_{2}$ via cyclic injections, Geophysical Research Letters, vol. 43, n¹8, p. 96779685, doi:10.1002/2016GL070304

Hesse, M.A., Orr Jr., F. M., and Tchelepi, H. A., 2008. Gravity currents with residual trapping, Journal of Fluid Mechanics, vol. 611, p. 35-60

Iglauer, S., Paluszny, A., Pentland, C. H., and Blunt, M., 2011. Residual CO2 imaged with X-ray micro-tomography, Geophysical Research Letters, vol. 38, doi:10.1029/2011GL049680

IPCC, 2005.Underground geologicalstorage.In: Metz, B., Davidson, O., deConinck, H. C., Loos, M., and Meyer, L. A. (eds)IPCC Special Report on Carbon DioxideCapture and Storage, prepared byWorking Group III of theIntergovernmental Panel on ClimateChange. Cambridge University Press,Cambridge, UK, and New York, USA, p 195-276

Juanes, R., Spiteri, E. J., Orr Jr., F. M., and Blunt, M., 2006. Impact of relative permeability hysteresis on geological CO2 storage, Water Resources Research, vol. 42, W12418, doi:10.1029/2005WR004806

Kak, A. C., and Slaney, M. 1987.Principles of computerized tomographic imaging.

Krohn, C.E., 1988, Sandstone fractal and Euclidean pore volume distributions, J. Geophys. Res., vol. 93, p. 3286-3296

Kroon, D., 2011. Patch Curvature,

http://www.mathworks.com/matlabcentral/fileexchange/32573-patch-curvature

Kumar, A., Ozah, R., Noh, M., Pope, G. A., Bryant, S., Sepehrnoori, K., and Lake, L. W. 2005. Reservoir simulation of $\mathrm{CO}_{2}$ storage in deep saline aquifers, SPE Journal, vol. 10, nº3, p. 336348

Kumar, M., Senden, T. J., Sheppard, A., Middleton, J. P., and Knackstedt, M. A., 2010.Vizualizaing and quantifying the residual phase distribution in core material, Petrophysics, vol. 51, $\mathrm{n}^{\circ}$ 5, p. 323-332

Li, X., and Yortsos, Y. C., 1991.Visualization and Numerical Studies of Bubble Growth during Pressure Depletion, SPE Annu. Tech. Conf. Exhib.,6-9 October, Dallas, Texas

Li, X., and Yortsos, Y. C., 1995. Theory of multiple bubble growth in porous media by solute diffusion, Chem. Eng. Sci., vol. 50, nº 8, p. 1247-1271

Lifshitz, I. M., and Slyozov, V. V., 1961. The kinetics of precipitation from supersaturated solid solutions, J. Phys. Chem. Solids, vol. 19, n 1-2, p. 35-50 
Lindquist, W. B., and Venkatarangan, A., 2000. Pore and throat size distributions measured from synchrotron X-ray tomographic images of Fontainebleau sandstones, Journal of Geophysical Research, vol. 105, nº B9, p. 21,509-21,527

McClure, J. E., Berrill, M. A., Gray, W. G., and Miller, C. T., 2016a. Tracking interface and common curvature dynamics for two-fluid flow in porous media, J. Fluid Mech., col. 796, p. 211-232, doi:10.1017/jfm.2016.212

McClure, J. E., Berrill, M. A., Gray, W. G., and Miller, C. T., 2016b. Influence of phase connectivity on the relationship among capillary pressure, fluid saturation and interfacial area in two-fluid-phase porous medium systems, Physical review E, vol. 94, 033102, doi:10.1103/PhysRevE.94.033102

Möller, J., Jacob, K., and Schmelzer, J., 1998. Ostwald ripening in porous viscoelastic materials, J. Phys. Chem. Solids, vol. 59, nº 6-7, p. 1097-1103

Paganin, D., Mayo, S.G., Gureyev, T.E., Miller, P.R., and Wilkins, S.W., 2002. Simoultaneous phase and amplitude extraction from a single defocused image of a homogeneous object, Journal of Microscopy, vol. 206, nº1, p. 33-40

Peyre, G., 2007. Graph theory toolbox,

http://www.mathworks.com/matlabcentral/fileexchange/5355-toolbox graph?s_tid=srchtitle

Prasad, M., 2001. Mapping impedance microstructures in rocks with acoustic microscopy, The Leading Edge, vol. 20, n 2, p. 172-179

Prodanovic, M., Lindquist, W. B., and Seright, R. S., 2007. 3D image-based characterization of fluid displacement in a Berea core, Advances in Water Resources, vol. 30, p. 214-226

Rücker, M., Berg, S., Armstrong, R. T., Georgiadis, A., Ott, H., Schwing, A., Neiteler, R., Brussee, N., Makurat, A., Leu, L., Wolf, M., Khan, F., Enzmann, F., and Kersten, M., 2015. From connected pathway flow to ganglion dynamics, Geophysical Research Letters, vol. 42, p. 3888-3894, doi:10.1002/2015GL064007

Schlüter, S., Sheppard, A. P., Brown, K., and Wildenschild, D., 2014.Image processing of multiphase images obtained via X-ray microtomography: A review,Water Resour. Res., vol. 50, no 4, p. 3615-3639

Schlüter, S., Berg, S., Rücker, M., Arsmtrong, R. T., Vogel, H. J., Hilfer, R., and Wildenschild, D., 2016. Pore-scale displacement mechanisms as a source of hysteresis for two-phase flow in porous media, Water Resources Research, vol. 52, p. 2194-2205, doi:10.1002/2015WR018254

Schmelzer, J., and Schweitzer, F., 1987. Ostwald Ripening of Bubbles in Liquid-Gas Solutions, J. Non-Equilibrium Thermodyn., vol. 12, nº 3, p. 255-270

Schmelzer, J., Möller, J., and Slezov, J. J. 1995. Ostwald ripening in porous materials: The case of arbitrary pore size distributions, J. Phys. Chem. Solids, vol. 56, nº 8, p. 1013-1022

Sok, R. M., Knackstedt, M. A., Sheppart, A. P., Pinczewski, W. V., Lindquist, W. B., Venkatarangan, A., and Paterson, L., 2002. Direct and stochastic generation of network models from tomographic images; effect of topology on residual saturations, Transport in Porous Media, vol. 46, p. 345-372

Sorkine, O., 2006. Differential representations for mesh processing, Computer Graphics Forum, 42 vol. $25, \mathrm{n}^{\circ} 4,789-807$ 
1 Tanino, Y, and Blunt, M. J., 2012. Capillary trapping in sandstones and carbonates: Dependence

2 on pore structure, Water Resour. Res., vol. 48, n 8, p. 1-13

3 Tomasi, C., and Maduchi, R., 1998. Bilateral filtering for gray and color images. $6^{\text {th }}$ International

4 Conference on Computer Vision, New Delhi, India. p. 839-846

5 Vargaftik, N. B., Volkov, B. N., and Voljak, L. D., 1983. International tables of the surface

6 tension of water, J. Phys. Chem. Ref. Data, vol. 12, nº3, p. 817-820

7 Voorhees, P. W., 1985. The theory of Ostwald Ripening, J. Stat. Phys., vol. 38, nº 1-2, p. 231-252

8 Wan, J., Kim, Y., and Tokunaga, T. K., 2014. Contact angle measurement ambiguity in

9 supercritical CO 2-water-mineral systems: Mica as an example, International Journal of

10 Greenhouse Gas Control, vol. 31, p. 128-137

11 Wang, S., Tokunaga, T. K., Wan, J., Dong, W., and Kim, Y., 2016. Capillary pressure-saturation

12 relations in quartz and carbonate sands: Limitations for correlating capillary and wettability

13 influences on air, oil, and supercritical CO2 trapping, Water Resrouces Research, vol. 52, $\mathrm{n}^{\circ} 2$,

14 p 6671-6690

15 Weitkamp, T., Haas, D., Wegrzynek, D., and Rack, A., 2011. ANKAphase: software for single-

16 distance phase retrieval from inline X-ray phase contrast radiographs, Journal of Synchrotron

17 Radiation, vol 18, nº4, p. 617-629

18 Wildenschild, D., and Sheppard, A. P., 2013. X-ray imaging and analysis techniques for

19 quantifying pore-scale structure and processes in subsurface porous medium systems,

20 Advances in Water resources, vol. 51, p. 217-246

21 Zimmerman, R.W. (1984), The effect of pore structure on the pore and bulk compressibilities of

22 consolidated sandstones, Ph.D. Thesis, University of California, Berkeley, 116 p 